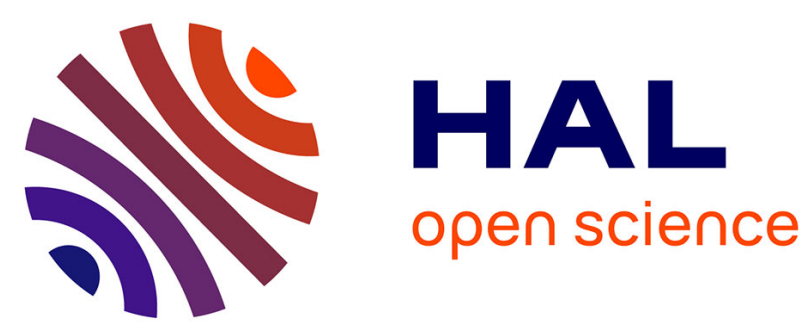

\title{
Mass transfer between a continuous oxide phase (U-O-Zr) and a steel droplet at liquid state: potential impact on corium pool behaviour during in-vessel melt retention
}

Romain Le Tellier

\section{To cite this version:}

Romain Le Tellier. Mass transfer between a continuous oxide phase (U-O-Zr) and a steel droplet at liquid state: potential impact on corium pool behaviour during in-vessel melt retention. Nuclear Engineering and Design, 2021, 385, pp.111525. 10.1016/j.nucengdes.2021.111525 . cea-03434619

\section{HAL Id: cea-03434619 \\ https://hal-cea.archives-ouvertes.fr/cea-03434619}

Submitted on 18 Nov 2021

HAL is a multi-disciplinary open access archive for the deposit and dissemination of scientific research documents, whether they are published or not. The documents may come from teaching and research institutions in France or abroad, or from public or private research centers.
L'archive ouverte pluridisciplinaire HAL, est destinée au dépôt et à la diffusion de documents scientifiques de niveau recherche, publiés ou non, émanant des établissements d'enseignement et de recherche français ou étrangers, des laboratoires publics ou privés.

\section{(1) $(1) \Theta$}

Distributed under a Creative Commons Attribution - NonCommercial - NoDerivatives $\mid 4.0$ 


\title{
Mass transfer between a continuous oxide phase (U-O-Zr) and a steel droplet at liquid state: potential impact on corium pool behaviour during in-vessel melt retention
}

\author{
R. Le Tellier ${ }^{\mathrm{a}, *}$ \\ ${ }^{a}$ CEA, DES, IRESNE, DTN, Cadarache \\ F-13108 Saint Paul-lez-Durance, France
}

\begin{abstract}
In the frame of light water reactors' severe accidents (SA), the success of a mitigation based on the core melt retention in the vessel lower head largely depends on the corium pool phases stratification. Such a melt is composed of molten partially oxidised materials relocated from the core and molten steel mainly coming from the ablation of lower head internal structures and the vessel wall during the transient. Because of the miscibility gap in the U-O-Zr-steel thermodynamic system at liquid state, such a pool can go through various stratified states during a transient with a heavy metal phase at the bottom or a light metal one at the top.

Actually, there is a significant knowledge gap related to steel migration to the pool that influences the stratification transient and can lead in some cases to a large uncertainty on the heat flux that the pool imposes on the vessel lower head. In particular, when the ablated vessel wall is considered, the molten steel relocation, either as a continuous lighter phase above the pool or as dispersed phase in the oxide pool, depends on the behaviour of the refractory crust at the pool/vessel interface (that can undergo dissolution or mechanical damage). In the case of a dispersed metal phase in the oxide pool, determining the subsequent state of the lower head pool requires the evaluation of the thermochemical interaction between both materials and their possible hydrodynamic separation. To the best of our knowledge, no model described these coupled phenomena in integral SA codes.

In this paper, an integral model is proposed to better assess the phenomena at stake in such a case and clarify the need (or not) to enhance stratified pool models in SA codes. To do so, this integral model was constructed on "first-order" hypotheses; in particular, thermal equilibrium is assumed and a simplified representation of the U-O-Zr-steel thermodynamic system is considered. The model has been implemented in the PROCOR software platform and used for a parametric analysis that provides insightful order of magnitudes and trends. The main parameters are the droplet size, the corium chemical composition and the model closures associated with interfacial mass transfer.

The results reported here show that mass transfer, "competing" with droplet hydrodynamics, plays an important role for droplets of millimetric size that can, depending on the pool composition, relocate under the oxide under the form of a continous heavy metal layer. For larger droplets, it is a light metal layer above the pool that can be expected. The prolonged existence of a dispersed metal phase that would remain mixed in the oxide phase seems to be only possible for a very narrow range of pool composition near the stratification inversion threshold.
\end{abstract}

Keywords: in-vessel melt retention, corium pool stratification, multicomponent diffusion, droplet hydrodynamics, lumped parameter model

\footnotetext{
* contact:

Email address: romain.le-tellier@cea.fr (R. Le Tellier)
} 


\section{Nomenclature}

\section{Greek letters}

$\Gamma$ interface between spatial domains $\Omega_{o x y}$ and $\Omega_{m e t}$

$\mu$ dynamic viscosity

$\nu$ kinematic viscosity $\nu=\frac{\mu}{\rho}$

Pa.s

$\mathrm{m}^{2} \cdot \mathrm{s}^{-1}$

$\Omega_{\star}$ spatial domain $\star$

$\varphi_{\star, \Gamma}^{p}$ average flux of property p through $\Gamma$

$\phi$ heat flux

$\rho$ mass density

$\sigma$ interfacial tension

Subscripts and superscripts

$j$ component index, $j \in\{O, U, Z r$, steel $\}$

met metal (discontinuous) phase

oxy oxide (continuous) phase

* met or oxy

Latin letters

$C_{Z r} \mathrm{Zr}$ molar oxidation index

$D$ mass diffusion coefficient

$d$ (resp. $r$ ) droplet (equivalent) diameter (resp. radius)

$H$ specific enthalpy

$h^{j, i} i j$-term of the mass transfer coefficient matrix

$h^{\mathrm{T}}$ heat transfer coefficient

$J^{j}$ component $j$ mass flux

$\dot{m}_{\star, \Gamma}$ total mass flow rate through $\Gamma$ (counted positive when leaving from $\Omega_{\star}$ )

$m_{\star}$ mass of $\Omega_{\star}$

$p_{\star, \Gamma} \dot{m}_{\star, \Gamma}$ transfer rate of property p out of $\Omega_{\star}$ through $\Gamma$

$p_{\star} m_{\star}$ mass averaged property $p$ over $\Omega_{\star}$

$\dot{q}^{\text {mass }}$ mass power density

$r^{0}$ initial radius of the steel spherical droplet

$R_{U / Z r} \mathrm{U} / \mathrm{Zr}$ molar ratio

$S$ area

$\dot{S}_{\star}^{p}$ mass averaged source of property p in $\Omega_{\star}$

$V$ volume

$v$ velocity norm

$v_{z} z$-axis velocity component

$w^{j}$ component $j$ mass fraction

$x_{\text {steel }}$ global initial mass ratio between steel and oxide $[\mathrm{p}] \cdot \mathrm{m}^{-2} \cdot \mathrm{s}^{-1}$

$\mathrm{W} . \mathrm{m}^{-2}$

$\mathrm{kg} \cdot \mathrm{m}^{-3}$

N.m ${ }^{-1}$

$\mathrm{m}^{2} \cdot \mathrm{s}^{-1}$

$\mathrm{m}$

${\mathrm{J} . \mathrm{kg}^{-1}}^{-1}$

$\mathrm{m}^{-1} \cdot \mathrm{s}^{-1}$

$\mathrm{W} \cdot \mathrm{m}^{-2} \cdot \mathrm{K}^{-1}$

$\mathrm{kg} \cdot \mathrm{m}^{-2} \cdot \mathrm{s}^{-1}$

$\mathrm{kg} \cdot \mathrm{s}^{-1}$

$\mathrm{kg}$

$[\mathrm{p}] . \mathrm{s}^{-1}$

[p]. $\mathrm{kg}^{-1}$

W. $\mathrm{kg}^{-1}$

$\mathrm{m}$

$\mathrm{m}^{2}$

$[\mathrm{p}] \cdot \mathrm{kg}^{-1} \cdot \mathrm{s}^{-1}$

$\mathrm{m}^{3}$

$\mathrm{m} . \mathrm{s}^{-1}$

m.s ${ }^{-1}$

\section{Introduction}

In the frame of the analysis of severe accidents in light water reactors, this work is related to the corium behaviour in the vessel lower head. Indeed, when considering an in-vessel retention strategy, 1, 2] such an analysis requires the transient simulation of the vessel wall ablation due to the heat flux imposed by the corium pool. Coupling both thermalhydraulics (natural convection in the liquids and conduction in the solid) and thermochemistry (phase segregation), the behaviour of the multiphase multicomponent corium pool is strongly affected by molten steel relocation to the pool associated with internal structures and vessel wall ablation.

In particular, the miscibility gap in the $U$-O-Zr-steel thermodynamic system induces complex liquid phases stratification transients in the pool that play major role on the boundary heat flux distribution. Past experimental programs on suboxidized corium-steel interactions (in particular, OECD MASCA [3]) 
have shown that the miscibility gap leads, at steady-state, to melt component partitioning into an oxygenrich ("oxide") phase and an oxygen-poor ("metal") phase. When their density difference is large enough, these two phases tend to stratify into a two-layer pool. For a low $\mathrm{Zr}$ oxidation degree $C_{Z r}$ or steel mass fraction $x_{\text {steel }}$, the metal phase density is higher than the oxide one (because of a relatively large mass fraction of uranium) and tends to decrease when $C_{Z r}$ or $x_{\text {steel }}$ increases. During the lower plenum transient, because of the progressive internal structures and vessel wall ablation, $x_{\text {steel }}$ increases such that the pool configuration evolves with different metal layers (as illustrated in Figure 1). Typically, a heavy metal layer at the bottom of the oxide melt can form and subsequently disappear during the transient. Accordingly, the thickness of a light metal layer in direct contact with the vessel wall will evolve with time with strong consequences on the associated heat flux to the vessel wall: either by the so-called heat flux "focusing effect" when its thickness is decreased or because of its sharp rising temperature when "hot" metal addition during stratification inversion.

As discussed in 4], key parameters that drive the pool stratification are the molten steel relocation into the pool and the mass transfer among the pool phases. The present works is related to such phenomena.

The molten steel relocation "path" to the pool is largely uncertain, in particular for the ablated vessel wall where it depends on the refractory crust behaviour (formation, possible dissolution by molten metal, mechanical stability). Accordingly, as discussed in [5], the different codes that simulate lower head transients exhibit differences in this matter: no actual modelling of the molten steel migration is used but different hypotheses are made. Considering the ASTEC (IRSN), HEFEST (IBRAE), MAAP_EDF (EPRI, EDF) ${ }^{1}$ and PROCOR codes, three different assumptions can be distinguished (as illustrated in Figure 1):

- considering that a possible interface crust is fully permeable, molten metal from a vessel area is incorporated into the melt at the same axial level ; this is the only option in ASTEC and a possible option in MAAP_EDF ("option 2" in Figure 1);

- considering crust non-permeability, molten metal is incorporated into the light metal layer ; this is the only option in HEFEST (each component of the arriving melt is distributed in accordance with the current stratification state) and a possible option in MAAP_EDF ("option 1" in Figure 1) and PROCOR;

- an intermediate option (controlled by user parameters) is available in PROCOR : part of the molten steel (mass fraction $\alpha$ in Figure 1) is incorporated on top of the pool and the rest is considered to enter the pool and rise through it to form a light metal layer below the axial crust.

When considering a permeable crust as in ASTEC or MAAP_EDF ("option 2"), some molten steel will be directly relocated into the oxidic melt. Physically, it would correspond to a configuration where a dispersed metal phase (droplets) is formed into the continuous oxide phase. This raises the question of the modelling associated with such a multiphase "zone" in the frame of lumped parameter thermal models.

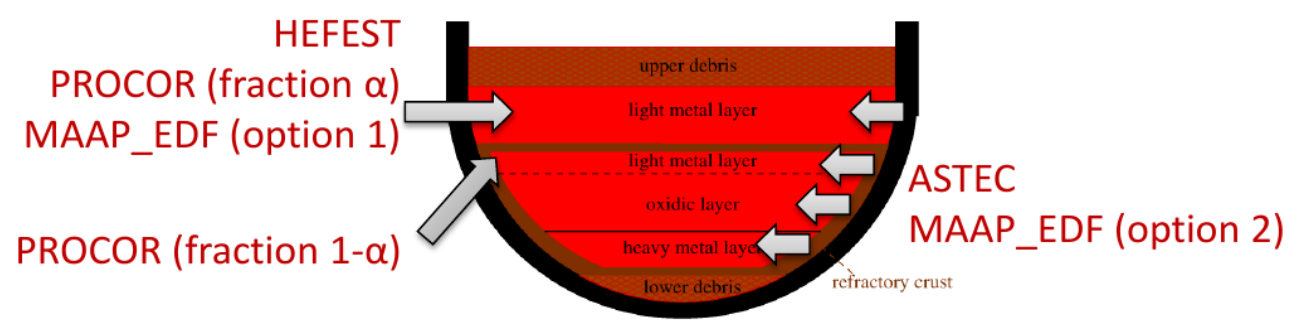

Figure 1: Schematic view of a stratified corium pool and associated molten steel relocation hypotheses used in different codes

In [6], we have studied the closures of the energy conservation equations associated with the different layers of a stratified pool. More precisely, we have tested different segregation hypotheses to construct

${ }^{1} \mathrm{MAAP}_{\text {EDF }}$ is the version of the MAAP (code developed by EPRI) comprising specific EDF models. 
from a thermodynamic database such closures in terms of enthalpy-temperature relations (as a function of composition). On a simple benchmark, it was observed that corium-steel chemical interaction and associated liquid phase separation have a very strong impact on the mixture enthalpy in such a way that a simple homogeneous treatment of a "zone" comprising both oxidic corium and molten steel is to be ruled out. In other words, on a case-by-case basis (depending on the phases initial topology), an explicit modelling of such phenomena is needed for such "zones".

\subsection{The starting point and the goal}

When considering the relocation of molten steel (from internal structures or vessel wall ablation) into the oxidic melt, to the best of our knowledge, no transient analysis of coupled corium-steel chemical interaction and phase separation between the metal droplets and the oxide phase has been reported. The objective of this work is to provide such a "first-order" analysis so that associated modelling issues can be clarified and conclusions can be drawn both in terms of R\&D needs and mandatory (or not) codes enhancement. This model focuses on the oxide layer and does not take into account the other possible continuous metal phases of an in-vessel stratified pool (as depicted in Figure 1). However, the analysis of the metal droplets behaviour in the oxide phase can already give insightful information about the possible consequences on the stratified pool evolution in the reactor case.

Taking into account the large uncertainty about the molten steel relocation "path" through the crust to the oxidic pool, this study will be parametric in nature considering, for the initial state of the system, a twophase configuration with dispersed molten steel phase into a continuous oxidic one. It will be based on an integral model constructed from "first-order" simplifying hypotheses so that a rather "simple" configuration is obtained and suitable for order of magnitudes and trends analyses.

In this paper, the model is detailed in Section 2 along with a limited set of numerical results in Section 3. After some verification tests, first trends analysis are presented and provide preliminary results for such a study that are discussed in views of the model underlying hypotheses. Conclusions and short perspectives are finally drawn in Section 4 .

\section{Modelling}

As discussed in Section 1, in this work, we will consider a closed system composed of a dispersed metallic liquid phase within a continuous oxidic one. In addition, the following hypotheses are made:

- H1 The metallic phase is considered to be mono-dispersed and the interaction between droplets are neglected i.e. they can be considered as isolated.

- H2 The convection in the continuous oxidic phase does not affect the droplets dynamics i.e. the oxidic phase is treated as stagnant.

Thanks to H 1 and $\mathrm{H} 2$, the system to be modelled can be restricted to a single pattern consisting of a single droplet within a given amount of oxidic corium. In such a case, the initial configuration can be fully defined in terms of $r^{0}$, the initial radius of the steel spherical droplet, $R_{U / Z r}$ (resp. $C_{Z r}$ ), the $U / Z r$ molar ratio (resp. the $Z r$ molar oxidation index) of the initial oxidic phase and $x_{\text {steel }}$, the overall initial mass ratio between steel and oxide into the pool. Such a two-zone configuration with the oxidic phase domain $\Omega_{o x y}$ separated from the metal droplet domain $\Omega_{m e t}$ by an interface $\Gamma$ is depicted in Figure 2 One should see Figure 2 as a zoom in on a representative elementary volume associated with a single metal droplet in the oxide layer of Figure 1 .

Note that the potential limitation associated with such hypotheses will be discussed a posteriori in the frame of the numerical results analysis. 


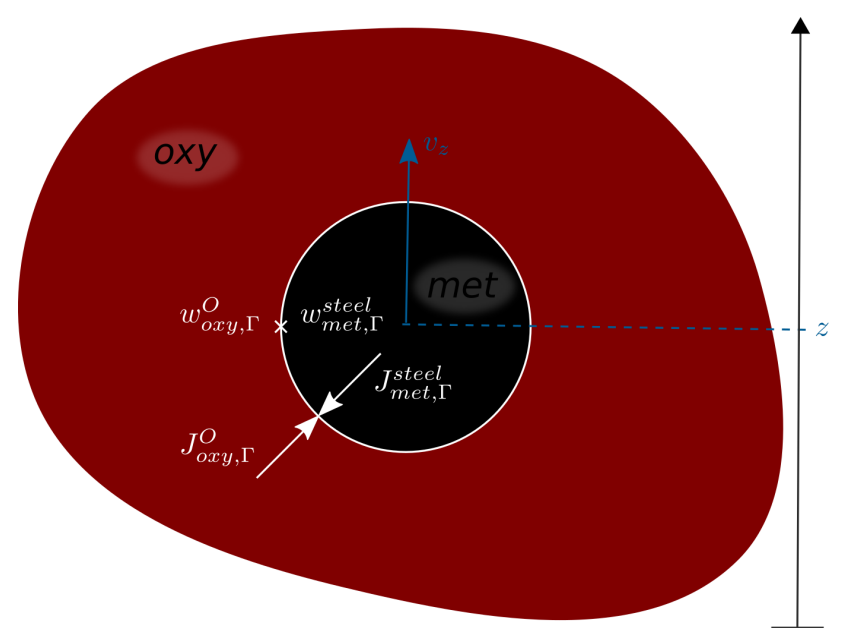

Figure 2: Schematic of the two-phase configuration with associated notations

\subsection{Isothermal hypothesis}

For the sake of this "first-order" analysis, the following additional hypothesis is considered:

- H3 Both zones $\Omega_{o x y}$ and $\Omega_{m e t}$ are in thermal equilibrium.

This is motivated by the fact that mass transfer is in any case far slower than heat transfer (indeed, the ratio of the thermal diffusivity over the mass diffusivity is $\sim 100-1000$ ). Note that $\mathrm{H} 3$ will be further discussed a posteriori in the frame of the numerical results analysis.

Under $\mathrm{H} 3$, the system of conservation equations will be written for a uniform (and fixed) value of temperature $T$. In the remainder, all calculations will be performed at $T=3000 \mathrm{~K}$.

\subsection{Mass and component mass conservation}

In this two-phase configuration, the mass conservation equation for $\Omega_{\star}(\star \in\{$ oxy, met $\})$ is simply:

$$
\frac{d m_{\star}}{d t}+\dot{m}_{\star, \Gamma}=0
$$

while the associated interface conditions on $\Gamma$ are given by:

$$
\dot{m}_{o x y, \Gamma}+\dot{m}_{m e t, \Gamma}=0
$$

In the remainder, the following notation is used: $\dot{m}_{\Gamma}=\dot{m}_{o x y, \Gamma}=-\dot{m}_{m e t, \Gamma}$.

Then, component mass conservation for $\Omega_{\star}(\star \in\{$ oxy, met $\})$ can be written in terms of $w^{j}$, the mass fraction of component $j \in\{O, U, Z r$, steel $\}\}^{2}$ as

$$
\begin{aligned}
\frac{d}{d t}\left(w_{o x y}^{j} m_{o x y}\right)+J_{o x y, \Gamma}^{j} S_{\Gamma}+w_{o x y, \Gamma}^{j} \dot{m}_{\Gamma} & =0 \\
\frac{d}{d t}\left(w_{m e t}^{j} m_{m e t}\right)+J_{m e t, \Gamma}^{j} S_{\Gamma}-w_{m e t, \Gamma}^{j} \dot{m}_{\Gamma} & =0
\end{aligned}
$$

where $\sum_{j} w^{j}=1$ and $\sum_{j} J_{\star, \Gamma}^{j}=0$ so that total mass conservation is enforced. Accordingly, in such a quaternary system, only three out of the four pairs of Eqs. 3 and 4 are in practice. The associated jump interface conditions on $\Gamma$ are given by:

$$
\left(w_{o x y, \Gamma}^{j}-w_{m e t, \Gamma}^{j}\right) \dot{m}_{\Gamma}+\left(J_{o x y, \Gamma}^{j}+J_{m e t, \Gamma}^{j}\right) S_{\Gamma}=0
$$

\footnotetext{
${ }^{2}$ Steel is considered as a pseudo-component here.
} 
along with interface fluxes written under the general form:

$$
J_{\star, \Gamma}^{j}=-\rho_{\star, \Gamma} \sum_{i} h_{\star}^{j, i}\left(w_{\star, \Gamma}^{i}-w_{\star}^{i}\right)
$$

where $\left(h_{\star}^{j, i}\right)_{j, i}$ is the mass transfer coefficient matrix that verifies $\sum_{j} h_{\star}^{j, i}=0$ so that $\sum_{j} J_{\star, \Gamma}^{j}=0$ is enforced.

\subsection{Interface equations closure under simplifying hypotheses regarding the thermodynamic system}

The closure of the interface jump condition Eq. 5 requires an hypothesis that relates the mass fractions on both sides of the interface. In the following, the following hypothesis will be made:

- H4 Local chemical equilibrium at the liquid/liquid interface is supposed to be maintained at all time.

Note that if $\mathrm{H} 3$ has not been considered, thermal local equilibrium would have been necessary to supplement $\mathrm{H} 4$ enforcing temperature continuity i.e. $T_{o x y, \Gamma}=T_{m e t, \Gamma}$. Under $\mathrm{H} 4$ for a given interface temperature, component mass fraction interface conditions can be reformulated as the following multivariate non-linear root-finding problem:

$$
\text { find }\left\{\begin{array}{l}
\left(w_{o x y, \Gamma}^{j}, w_{m e t, \Gamma}^{j}\right) \in\left\{\left(w_{o x y, e q}^{j}, w_{m e t, e q}^{j}\right)\right\}_{e q} \text { such that Eq. } 5 \text { holds true } \\
\dot{m}_{\Gamma}
\end{array}\right.
$$

where $\left\{\left(w_{o x y, e q}^{j}, w_{m e t, e q}^{j}\right)\right\}_{e q}$ is the set of possible two-phase equilibrium mass fractions in the miscibility gap of the $\{O, U, Z r$, steel $\}$ system i.e. the tie-lines in the two-liquid region of the associated phase diagram.

For a $n$-component system, these equations defines a system of $(n-1)$ non-linear equations whose unknowns are $\dot{m}$ and $(n-2)$ chemical potentials. This "classical" condition at play in 1D sharp moving interface models such as those of the DICTRA commercial code [7] requires an iterative procedure that was found increasingly demanding and non-robust as the number of components increases [8]. In [9], considering the solidification of oxidic corium $(U-O-Z r$ system) where a variant of such jump conditions is involved, solving this root-finding problem was found impossible in many cases.

Taking into account this possible complexity, in this "first-order" study, we have chosen to simplify the pseudo-quaternary system $\{O, U, Z r$, steel $\}$ taking into account hypotheses reported in the literature on in-vessel corium liquid miscibility gap:

- H5 The U/Zr molar ratio is assumed to be uniform over the two phases i.e. $R_{o x y}^{U / Z r}=R_{m e t}^{U / Z r}=R_{U / Z r}$ [10, 11].

- H6 $\Omega_{o x y}$ (resp. $\Omega_{m e t}$ ) is supposed not to contain any steel component (resp. oxygen) i.e. $w_{o x y}^{\text {steel }}=0$ $\left(\right.$ resp. $\left.w_{m e t}^{O}=0\right)[11$.

Under $\mathrm{H}[5$ and $\mathrm{H} 6$, the pseudo-quaternary system $\{O, U, Z r$, steel $\}$ is reduced to two pseudo-binary systems: $(U, Z r)+O$ for the oxide phase and $(U, Z r)+$ steel for the metal phase. Accordingly, the mass transfer can now be fully described by:

$$
\begin{aligned}
\frac{d}{d t}\left(w_{\text {oxy }}^{O} m_{\text {oxy }}\right) & =0 \\
\frac{d}{d t}\left(w_{m e t}^{\text {steel }} m_{m e t}\right) & =0 \\
w_{\text {oxy }, \Gamma}^{O} \dot{m}_{\Gamma}+J_{\text {oxy }, \Gamma}^{O} S_{\Gamma} & =0 \\
-w_{\text {met }, \Gamma}^{\text {stee }} \dot{m}_{\Gamma}+J_{\text {met }, \Gamma}^{\text {stee }} S_{\Gamma} & =0
\end{aligned}
$$


In a binary system, only one out of two element mass conservation equations needs to be explicitly written. In the present case, while it is $(U, Z r)$ that is transferred through $\Gamma$, considering $O$ (resp steel) for writing the element mass conservation equation in the oxide (resp. metal) phase leads to equations better suited for further numerical treatment. Indeed, under H6, Eq. 8 (resp. Eq. 9) simply states that all the oxygen (resp. steel) remains in the oxide (resp. metal) phase.

The mass fluxes are expressed as:

$$
\begin{aligned}
& J_{\text {oxy }, \Gamma}^{O}=-\rho_{\text {oxy }, \Gamma} h_{\text {oxy }, \text { eff }}^{O}\left(w_{\text {oxy }, \Gamma}^{O}-w_{\text {oxy }}^{O}\right) \\
& J_{\text {meel }, \Gamma}^{\text {stel }}=-\rho_{\text {met }, \Gamma} h_{\text {met }, \text { eff }}^{\text {stee }}\left(w_{\text {met }, \Gamma}^{\text {steel }}-w_{\text {met }}^{\text {steel }}\right)
\end{aligned}
$$

where $h_{o x y, \text { eff }}^{O}$ and $h_{m e t, e f f}^{\text {steel }}$ are effective mass transfer coefficients. Eqs. 10 and 11 can be combined in order to get:

$$
J_{o x y, \Gamma}^{O} w_{m e t, \Gamma}^{\text {steel }}+J_{m e t, \Gamma}^{\text {steel }} w_{o x y, \Gamma}^{O}=0
$$

Under the hypothesis of local equilibrium at the interface, $w_{m e t, \Gamma}^{\text {steel }}$ and $w_{o x y, \Gamma}^{O}$ are linked together as they should belong to a same tie-line. Considering that the possible equilibrium conditions can be characterised by a function $f: w_{o x y, e q}^{O} \mapsto w_{m e t, e q}^{\text {steel }}=f\left(w_{o x y, e q}^{O}\right)$, this means that interface conditions are associated with the following non-linear root-finding problem:

$$
\text { find } w_{o x y, \Gamma}^{O} \text { such that }\left\{\begin{array}{c}
\rho_{o x y, \Gamma} h_{\text {oxy }, \text { eff }}^{O}\left(w_{\text {oxy }, \Gamma}^{O}-w_{\text {oxy }}^{O}\right) f\left(w_{\text {oxy }, \Gamma}^{O}\right)+ \\
\rho_{\text {met }, \Gamma} h_{\text {met }, \text { eff }}^{\text {stee }}\left(f\left(w_{\text {oxy }, \Gamma}^{O}\right)-w_{\text {met }}^{\text {steel }}\right) w_{\text {oxy }, \Gamma}^{O}=0
\end{array}\right.
$$

\subsection{Mass transfer related closures}

At this stage, it is considered that $h_{\text {oxy }, \text { eff }}^{O}\left(\right.$ resp. $\left.h_{m e t, e f f}^{\text {steel }}\right)$ is to be obtained from the following Sherwood number $S h_{o x y}=\frac{h_{o x y, e f f}^{O} d}{D_{o x y}}$ (resp. $S h_{m e t}=\frac{h_{m e t, e f f}^{\text {steel }} d}{D_{m e t}}$ ) where $d$ is the droplet (equivalent) diameter and $D_{o x y}$, an effective diffusion for $\mathrm{O}$ in the oxide phase (resp. $D_{m e t}$, an effective diffusion for steel in the metallic phase).

For the oxide phase under intense natural convection, "standard" heat transfer correlations provide information about heat transfer at the pool external boundary that can be used, through an analogy between heat and mass transfers (as in [12]) to get information about mass transfer at the same boundary. An order of magnitude for the associated Sherwood number is $\sim 10^{4}$. Regarding "internal" heat (or mass) transfer towards an embedded dispersed metal phase, to the best of the author's knowledge, no correlation is available. Accordingly, in our numerical simulations, $S h_{o x y}$ will first be taken as $10^{4}$ and then lowered by one order of magnitude for the sake of comparison.

For the dispersed metallic phase, two different kinds of data exists in the literature to get information about the droplet internal mass transfer:

- Computational Fluid Dynamics (CFD) simulations can provide meaningful data when an "idealized" droplet is considered. It has the advantage that the input parameters (along with the limitations in terms of the physical effects taken into account) are clearly identified. In practice, detailed parametric studies suitable for constructing a mass transfer correlation are limited to the case of a rigid spherical droplet with a motionless interface;

- Many correlations have been proposed in the literature based on various (and often, heterogeneous) experimental results. While they cover a broader range of input parameters (in particular, covering the transition and oscillatory regimes of the droplet interface deformation), they are based on experiments that often introduce additional physical effects (e.g. Marangoni effect) associated with the material properties that are not well "controlled" and distinguished one from the other in such the way that the application of an associated correlation to other materials is not straightforward. 
Taken into account the pros and cons of both approaches, the two were considered in this study for comparative purpose.

For a CFD-based $S h_{\text {met }}$ correlation, results reported in 13 obtained for the transfer inside a rigid circulating sphere are considered. For moderate Reynolds numbers, [13] reports simulations for gas-liquid, liquid-liquid, and liquid-gas (bubbles) systems with different viscosity ratios. Here, we focus on the liquidliquid system (viscosity and density ratios between continuous and discontinuous phases equal to 1) for which simulations were carried out over the following domain:

$$
\begin{aligned}
& 0 \leq \quad R e_{m e t}=\frac{v d}{\nu_{m e t}} \quad \leq 10^{2} \\
& 1 \leq P e_{m e t}=\frac{v d}{D_{m e t}} \quad \leq 10^{4}
\end{aligned}
$$

These results are fully consistent with the asymptotic limits $S h_{m e t}\left(R e_{m e t}=0, P e_{m e t}=0\right)=\frac{2 \pi^{2}}{3} \approx 6.58$ and $S h_{\text {met }}\left(R e_{\text {met }} \rightarrow 0, P e_{\text {met }} \rightarrow \infty\right) \approx 17.90$ (see [13]). Then, following the approach proposed in [14] for gas bubble, we have constructed a correlation for a normalised Sherwood number:

$$
S h_{m e t}^{\star}=\frac{S h_{m e t}\left(R e_{m e t}, P e_{m e t}\right)-S h_{m e t}\left(R e_{m e t}=0, P e_{m e t}=0\right)}{S h_{m e t}\left(R e_{m e t}, P e_{m e t} \rightarrow \infty\right)-S h_{m e t}\left(R e_{m e t}=0, P e_{m e t}=0\right)}
$$

as a function of the Péclet number $P e_{\max }=\frac{v_{\max }}{v} P e$ associated with the maximal velocity $v_{\max }$ at the bubble interface. More precisely, considering for $\frac{v_{\max }}{v}$, the relation proposed in [15]:

$$
\frac{v_{\max }}{v}=\frac{1}{2} \frac{16+3.315\left(\frac{\nu_{m e t}}{\nu_{o x y}} R e_{m e t}\right)^{1 / 2}+3\left(\frac{\nu_{m e t}}{\nu_{o x y}} R e_{m e t}\right)}{16+3.315\left(\frac{\nu_{m e t}}{\nu_{o x y}} R e_{m e t}\right)^{1 / 2}+\left(\frac{\nu_{m e t}}{\nu_{o x y}} R e_{m e t}\right)}
$$

the two following parameterised functions were considered:

$$
\begin{aligned}
S h_{m e t}^{\star} & =\frac{1}{1+\exp \left[-a\left(\ln \left(\frac{v_{m a x}}{v} P e_{m e t}\right)-b\right)\right]} \\
S h_{m e t}\left(R e_{m e t}, P e_{m e t} \rightarrow \infty\right) & =S h_{m e t}\left(R e_{m e t} \rightarrow 0, P e_{m e t} \rightarrow \infty\right)\left(c+d R e_{m e t}\right)
\end{aligned}
$$

The solution of the non-linear least-square problem associated to the fitting of these functions parameters gives $a \approx 1.9236990, b \approx 4.0917971, c \approx 1.0024819, d \approx 0.0008920$. The error on $S h$ associated with this fit is limited to $3 \%$. In the remainder, this CFD-based $S h_{m e t}$ correlation will be referred as Juncu2010.

Alternatively, for an experiment-based $S h_{m e t}$ correlation, based on the review in [16], a variant of the Kumar \& Hartland correlation [17] will also be considered under the following form:

$$
S h_{m e t}=S h_{m e t}\left(R e_{m e t} \rightarrow 0, P e_{m e t} \rightarrow \infty\right)+\beta \frac{3.19 \cdot 10^{-3}\left(\frac{\nu_{m e t}}{\nu_{o x y}} \operatorname{Re}_{m e t}^{2 / 3} P e_{m e t}^{1 / 3}\right)^{(1+\alpha)}}{1+1.43 \cdot 10^{-2}\left(\frac{\nu_{m e t}}{\nu_{\text {oxy }}} \operatorname{Re}_{\text {met }}^{2 / 3} P e_{m e t}^{1 / 3}\right)^{\alpha}}
$$

with $\beta=\frac{\left(\frac{\rho_{m e t}}{\rho_{\text {oxy }}}\right)^{2 / 3}}{1+\left(\frac{\mu_{\text {met }}}{\mu_{\text {oxy }}}\right)^{2 / 3}}$ and $\alpha=0.5$.

In particular, as discussed in [16], the $\alpha=0.5$-value provides an improvement w.r.t. the initial $\alpha=0.7$ value proposed in [17] when mass transfer from the continuous phase to the dispersed one is considered. In the remainder, this experiment-based $S h_{m e t}$ correlation will be referred as Wegener2014.

Such a correlation has been established for a wider range of Reynolds number in such a way that mass transfer regimes where the droplet is deformed are covered. However, one should note that, surprisingly, no dependency to the interfacial tension $\sigma$ appears in Eq. 19. Actually, in [17], it is claimed that the capillary number $C a=\frac{W e}{R e}$ effect was found negligible in the $\sigma$-range of $[0.8,35] \mathrm{mN}_{\text {. }}{ }^{-1}$ covered by the experimental 
results. Considering a $\mathrm{UO}_{2}$-steel interface, in [18, $\sigma$ was evaluated by the Girifalco \& Good model [19] at $360 \mathrm{mN} \cdot \mathrm{m}^{-1}$ i.e. a value, one order of magnitude larger than the upper value considered in [17]. As a consequence, the expected impact of interfacial tension (in particular as a counteraction to the droplet deformation) in our case is not captured by Wegener2014.

In a more general way, none of these two correlations is to be considered as strictly valid for the present application where, in the numerical results of Section 3 for $r^{0} \in\{0.1,1,5\} \mathrm{cm}, R e_{m e t}$ and $P e_{m e t}$ varies in very large range $\left(0 \leq R e_{m e t} \leq 10^{4}, 1 \leq P e_{m e t} \leq 10^{6}\right)$. However, because of the difference in the underlying approaches, they are meaningful in this "first-order" analysis to get a range of variations for $S h_{m e t}$ in a parametric study. As depicted in Figure 3, while both correlations give close results in the $10^{2} \leq P e_{m e t} \leq 10^{3}$ range they differ by one order of magnitude for large $R e_{m e t}$.

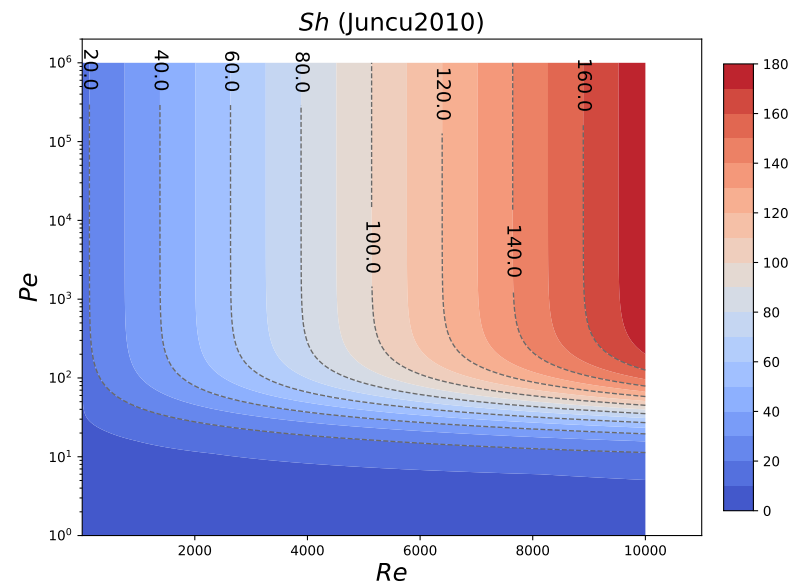

(a) Juncu2010 correlation

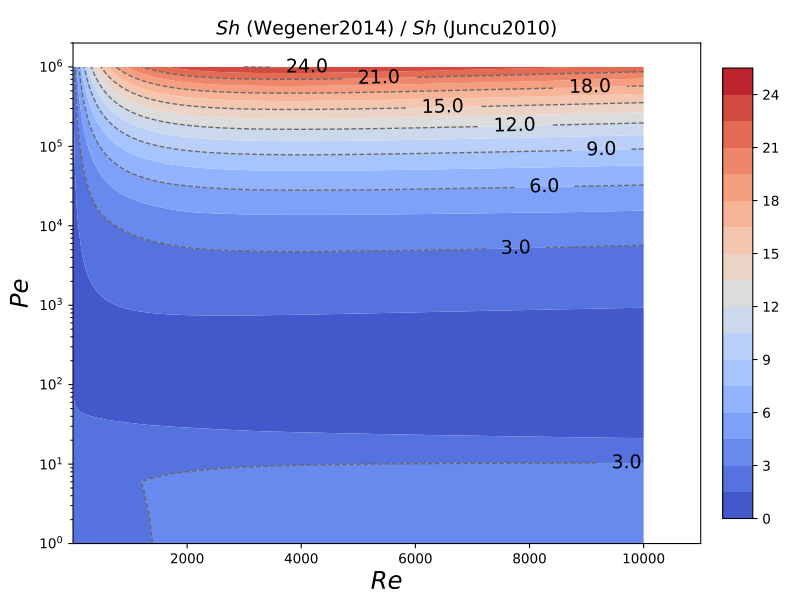

(b) ratio between Wegener2014 and Juncu2010 correlations

Figure 3: Sherwood number as evaluated from Juncu2010 and Wegener2014 correlations for $0 \leq R e \leq 10^{4}, 1 \leq P e \leq 10^{6}$

When discussing the impact of such a correlation, the results will have to be related to the most probable regime regarding the droplet interface deformation. To do so, we will consider two different criteria associated with a critical value of the Weber number (ratio between inertia force and interfacial tension) $W e=\frac{\rho_{o x y} v^{2} d}{\sigma}$ that characterises a threshold beyond which the spherical regime is lost: [16, 20]

$$
\begin{aligned}
W e_{\text {crit }} & =4 \\
W e_{\text {crit }} \cdot R e_{\text {crit }}^{0.65} & =165
\end{aligned}
$$

\subsection{Droplet dynamics}

Mass transfer is dependent on the droplet (rising or falling) velocity with respect to the oxide phase. Assuming a stagnant oxide liquid (see H2), considering a metallic droplet of volume $V_{m e t}$, the 1D momentum equation for $v_{z}$ velocity can be written as:

$$
\frac{d}{d t}\left[\left(\rho_{m e t}+C_{M} \rho_{o x y}\right) V_{m e t} v_{z}\right]=V_{m e t}\left(\rho_{o x y}-\rho_{m e t}\right) g-\operatorname{sign}\left(v_{z}\right) \frac{1}{2} C_{D} S_{\perp} \rho_{m e t} v_{z}^{2}
$$

where $C_{M}$ is the virtual mass coefficient, $C_{D}$ is the drag coefficient and $S_{\perp}=\frac{\pi d^{2}}{4}$.

Semi-empirical closure laws have then to be selected for $C_{M}$ and $C_{D}$. For a rigid sphere in a fluid, $C_{M}=\frac{1}{2}$. For $C_{D}$, the general correlation proposed in [21] is considered under the form introduced in [22]:

$$
C_{D}=\max \left\{\min \left[\max \left(\frac{16}{\frac{\nu_{m e t}}{\nu_{\text {oxy }}} R e_{\text {met }}}, \frac{13.6}{\left(\frac{\nu_{\text {met }}}{\nu_{\text {oxy }}} R e_{\text {met }}\right)^{4 / 5}}\right), \frac{48}{\frac{\nu_{\text {met }}}{\nu_{\text {oxy }}} R e_{\text {met }}}\right], \min \left[\frac{E o}{3}, 0.47 E o^{1 / 4} W e^{1 / 2}, \frac{8}{3}\right]\right\}
$$


with $E o=\frac{\left|\rho_{o x y}-\rho_{m e t}\right| g d^{2}}{\sigma}$, the Eötvös number (ratio between gravitional force and interfacial tension).

\section{Numerical results and analysis}

\subsection{Model implementation}

The model described in Section 2 has been developed as a stand-alone model in the frame of the PROCOR software platform [23].

Species mixture physical properties (at liquid state) are mostly obtained from the laws proposed in the CORPRO database [24] and available in PROCOR through an interface with the TOLBIAC-ICB code 25]. The interfacial tension between both liquid phases was taken constant equal to $360 \mathrm{mN} \cdot \mathrm{m}^{-1}$ (see Section 2.4 . For the effective diffusion coefficients, $D_{o x y}$ is taken equal to $5 \cdot 10^{-9} \mathrm{~m}^{2} \cdot \mathrm{s}^{-1}$. This order of magnitude is consistent with $\mathrm{U}$ and $\mathrm{O}$ self-diffusion coefficients in molten $\mathrm{UO}_{2}$ as evaluated by molecular dynamics simulations in [26] and close to the optimal value for the effective uranium diffusion coefficient in the oxide phase to be used when comparing PROCOR stratification model to MASCA-RCW experiment, see [23. Without further information about the diffusion in the metallic phase, for $D_{m e t}$, both $5 \cdot 10^{-9} \mathrm{~m}^{2} \cdot \mathrm{s}^{-1}$ and $5 \cdot 10^{-8} \mathrm{~m}^{2} \cdot \mathrm{s}^{-1}$ will be considered for a parametric analysis. The higher value is associated with a evaluation with the Stokes-Einstein formula (see [12]).

Thermodynamic equilibrium in the U-O-Zr-steel system is evaluated from the NUCLEA database [27, 28, version 17.1 with the OpenCalphad code [29] as interfaced in PROCOR [30].

From the point of view of the time discretization and the coupling between mass conservation equations and droplet dynamics, a semi-explicit scheme is used. Considering a time step between $t^{n}$ and $t^{n+1}=t^{n}+\Delta t$ with $\Delta t$ varying in $\left[10^{-3}, 10^{-2}\right] \mathrm{s}$, it proceeds as follows:

1. droplet radius and physical properties are taken constant equal to their values at $t^{n}$ for the integration of Eq. 22 from $t^{n}$ to $t^{n+1}$ by a five-step Adams-Moulton scheme (with an adaptive time step in $\left.\left[10^{-8}, 0.1 \Delta t\right]\right)$

2. droplet velocity at $t^{n+1}$ is used to evaluate $S h_{m e t}$.

3. considering $w_{o x y, \Gamma}^{O}$ and $w_{m e t}^{\text {steel }}$ equal to their values at $t^{n}$, the interface mass fractions are obtained by the solution of Eq. 15 through a Brent algorithm and $\dot{m}$ is calculated so that both phase masses can be evaluated explicitly at $t^{n+1}$ by $m_{\star}\left(t^{n+1}\right)= \pm \dot{m}_{\Gamma} \Delta t+m_{\star}\left(t^{n}\right)$;

4. mass fractions, physical properties and droplet radius are finally updated at $t^{n+1}$.

\subsection{Construction of the thermodynamic closure}

In Section 2 , it was assumed that, after simplification of the thermodynamic system through $\mathrm{H} 5$ and H6. the link between $w_{m e t, \Gamma}^{\text {steel }}$ and $w_{o x y, \Gamma}^{O}$ could be expressed in terms of a function $f: w_{o x y, e q}^{O} \mapsto w_{m e t, e q}^{\text {steel }}=$ $f\left(w_{\text {oxy }, e q}^{O}\right)$.

Before discussing the actual construction of $f$, let us go back to $\mathrm{H} 5$ and $\mathrm{H} 6$ that were deemed as acceptable in [11]. In order to do so, a series of thermodynamic equilibrium calculations in conditions relevant for PWR in-vessel corium applications were carried out with $T=3000 \mathrm{~K}, R_{U / Z r}=1.2$, varying $C_{Z r} \in\{0.3,0.5,0.7,0.9\}$ and $x_{\text {steel }} \in\left[5 \cdot 10^{-3}, 1.0\right]$. Two different steel compositions were considered: either pure- $\mathrm{Fe}$ steel or a stainless steel with the following mass fractions $\{68.67 \% \mathrm{Fe}, 20.72 \% \mathrm{Cr}, 10.61 \% \mathrm{Ni}\}$.

In all cases, $\mathrm{H} 6$ seems legitimate as these calculations indicate that $w_{o x y}^{\text {steel }}$ and $w_{m e t}^{O}$ remain small:

- $w_{\text {oxy }}^{\text {steel }}$ remains between $3 \cdot 10^{-3}$ and $1.2 \cdot 10^{-2}$ for stainless steel and between $2 \cdot 10^{-3}$ and $3.1 \cdot 10^{-3}$ for pure- $F$ e steel;

- $w_{m e t}^{O}$ remains between $5 \cdot 10^{-3}$ and $1.5 \cdot 10^{-2}$ for stainless steel and between $4 \cdot 10^{-3}$ and $1.3 \cdot 10^{-2}$ for pure-Fe steel. 
The results of these equilibrium calculations in terms of $R_{o x y}^{U / Z r}, R_{m e t}^{U / Z r}$ are given in Figures 4 and 5. In [11], only pure- $F e$ steel was considered but one can see that the difference between $R_{o x y}^{U / Z r}$ and $R_{\text {met }}^{U / Z r}$ is more pronounced for stainless steel. The validity of $\mathrm{H}[5$ is more questionable because the preferential extraction of $Z r$ w.r.t. $U$ in the metallic phase is more important: in comparison with $R_{U / Z r}=1.2, R_{\text {met }}^{U / Z r}$ is between $20 \%$ and $30 \%$ lower for stainless steel in comparison with $4 \%$ to $25 \%$ lower for pure- $F e$ steel.

In this "first-order" study, this hypothesis, that does no affect the qualitative behaviour of the system, will not be further questioned for the sake of simplicity and numerical robustness of the resulting model. However, one should keep in mind that it is a limiting hypothesis.
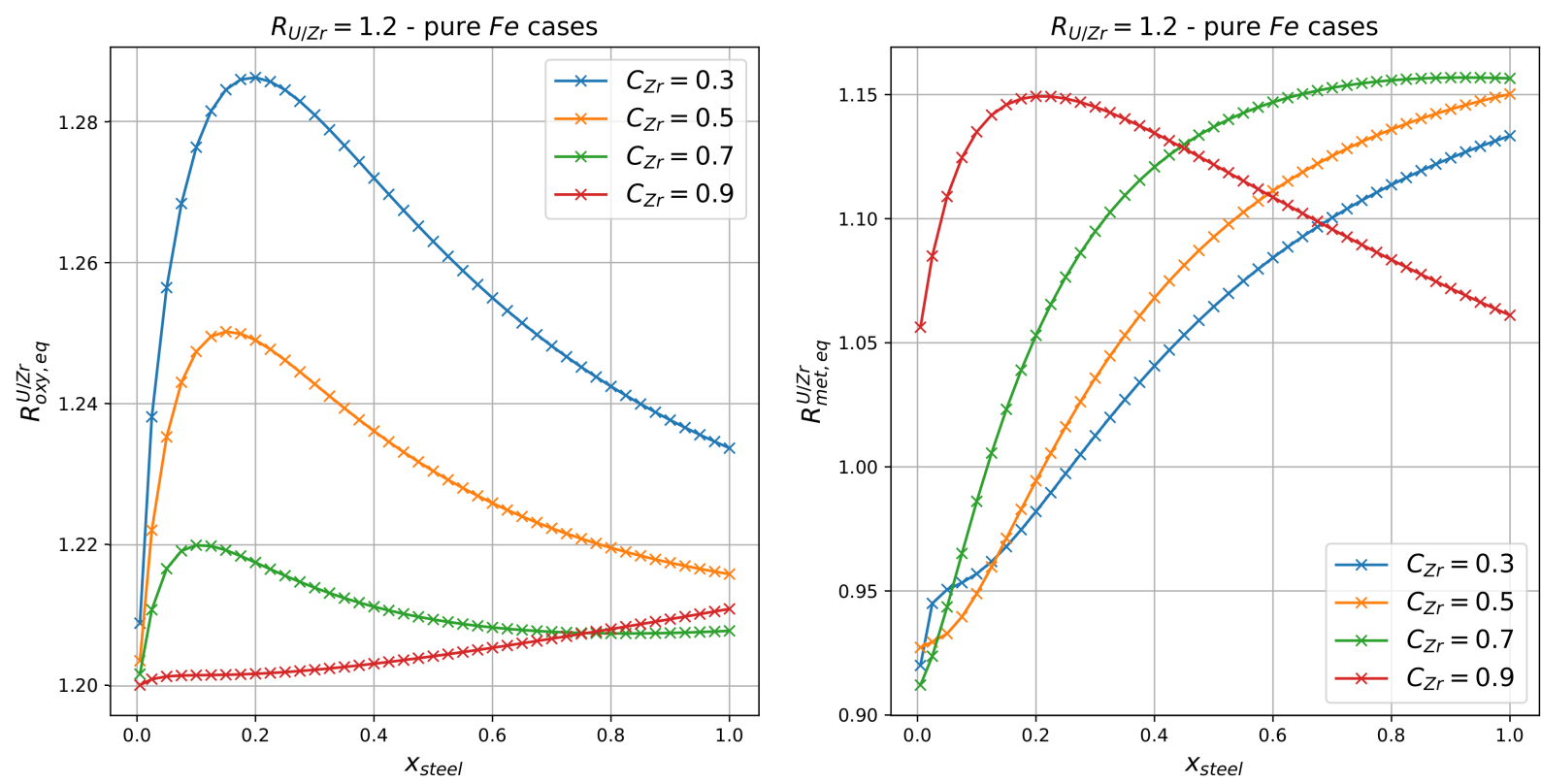

Figure 4: $R_{o x y}^{U / Z r}, R_{m e t}^{U / Z r}$ at equilibrium for $R_{U / Z r}=1.2, C_{Z r} \in[0.3,0.9], x_{\text {steel }} \in\left[5 \cdot 10^{-3}, 1\right]-$ steel $=\{F e\}$ case 

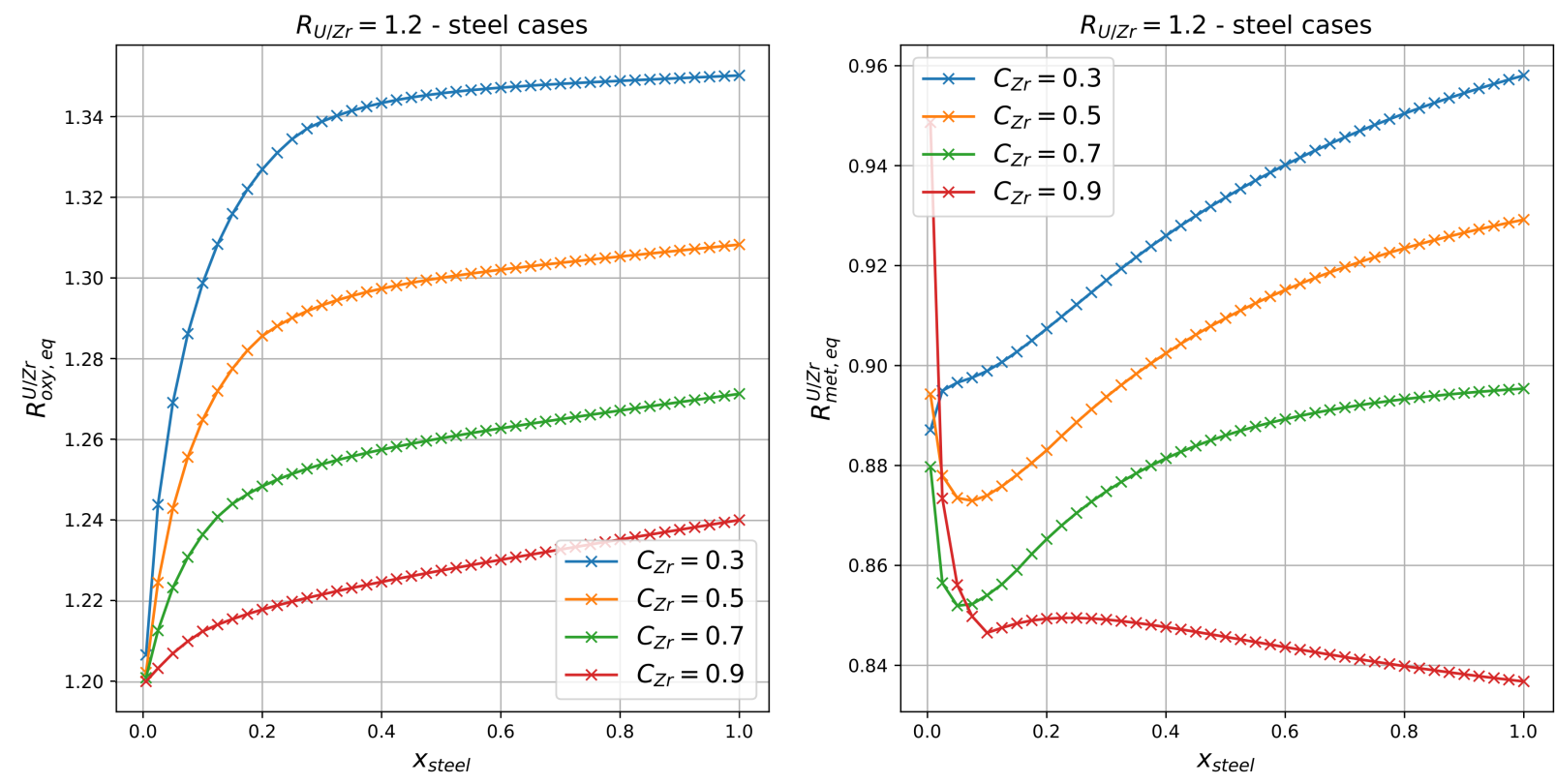

Figure 5: $\quad R_{\text {oxy }}^{U / Z r}, R_{\text {met }}^{U / Z r}$ at equilibrium for $R_{U / Z r}=1.2, \quad C_{Z r} \in[0.3,0.9], x_{\text {steel }} \in\left[5 \cdot 10^{-3}, 1\right]-$ steel $=$ $\{68.67 \% \mathrm{Fe}, 20.72 \% \mathrm{Cr}, 10.61 \% \mathrm{Ni}\}$ case

Regarding the construction of $f$, in practice, it can be obtained from a set of thermodynamic equilibrium calculations, denoted $\left\{e q_{i}\right\}_{i}$, for given $T, R_{U / Z r}$ and $C_{Z r}$, varying $x_{\text {steel }}$. Two different approaches have been tested:

- $f$ can be straightforwardly constructed from $\left(w_{o x y, e q_{i}}^{O}, w_{m e t, e q_{i}}^{\text {steel }}\right)_{i}$, the mass fractions of oxygen in the oxide and steel in the metal as retrieved from these equilibrium results;

- alternatively, in order to preserve the phase partitioning at equilibrium (i.e. $\frac{m_{m e t, e q_{i}}}{m_{o x y, e q_{i}}}$ for $e q_{i}$ equilibrium), another function denoted $\tilde{f}$ can be constructed from $\left(\frac{m_{\text {tot }}^{O}}{m_{\text {oxy } e_{i}}}, \max \left(\frac{m_{\text {tot }}^{\text {stel }}}{m_{m e t, e q_{i}}}, 1\right)\right)_{i}$, the mass fractions of oxygen in the oxide and steel in the metal evaluated in agreement with $\mathrm{H}\left[5\right.$ and $\mathrm{H} 6$, $m_{\text {tot }}^{O}$ (resp. $m_{t o t}^{\text {steel }}$ ) being the total mass of oxygen (resp. steel). However, note that for large $C_{Z r}$ and small $x_{\text {steel }}, \frac{m_{t o t}^{\text {stee }}}{m_{m e t, e q_{i}}}$ can become greater than 1 because of the small mass of metal phase at equilibrium and $w_{\text {oxy }}^{\text {steel }} \neq 0$; it has then to be limited to 1.

In both cases, a piecewise linear interpolation (with prolongation to $\left.\left(w_{o x y}^{O}=0, w_{m e t}^{\text {steel }}=1\right)\right)$ is used to construct the actual function. Such functions are depicted in Figure 6 based on equilibrium calculations for $R_{U / Z_{r}}=1.2$, varying $C_{Z r} \in\{0.3,0.5,0.7,0.9\}$ and $x_{\text {steel }} \in\left[5 \cdot 10^{-3}, 1.0\right]$. A non-monotonous behavior of $\tilde{f}$ when $w_{o x y}^{O}$ is decreased (i.e. for "small" $x_{\text {steel }}$ values) can clearly be seen. The possible impact on the model behaviour will be discussed afterwards. 

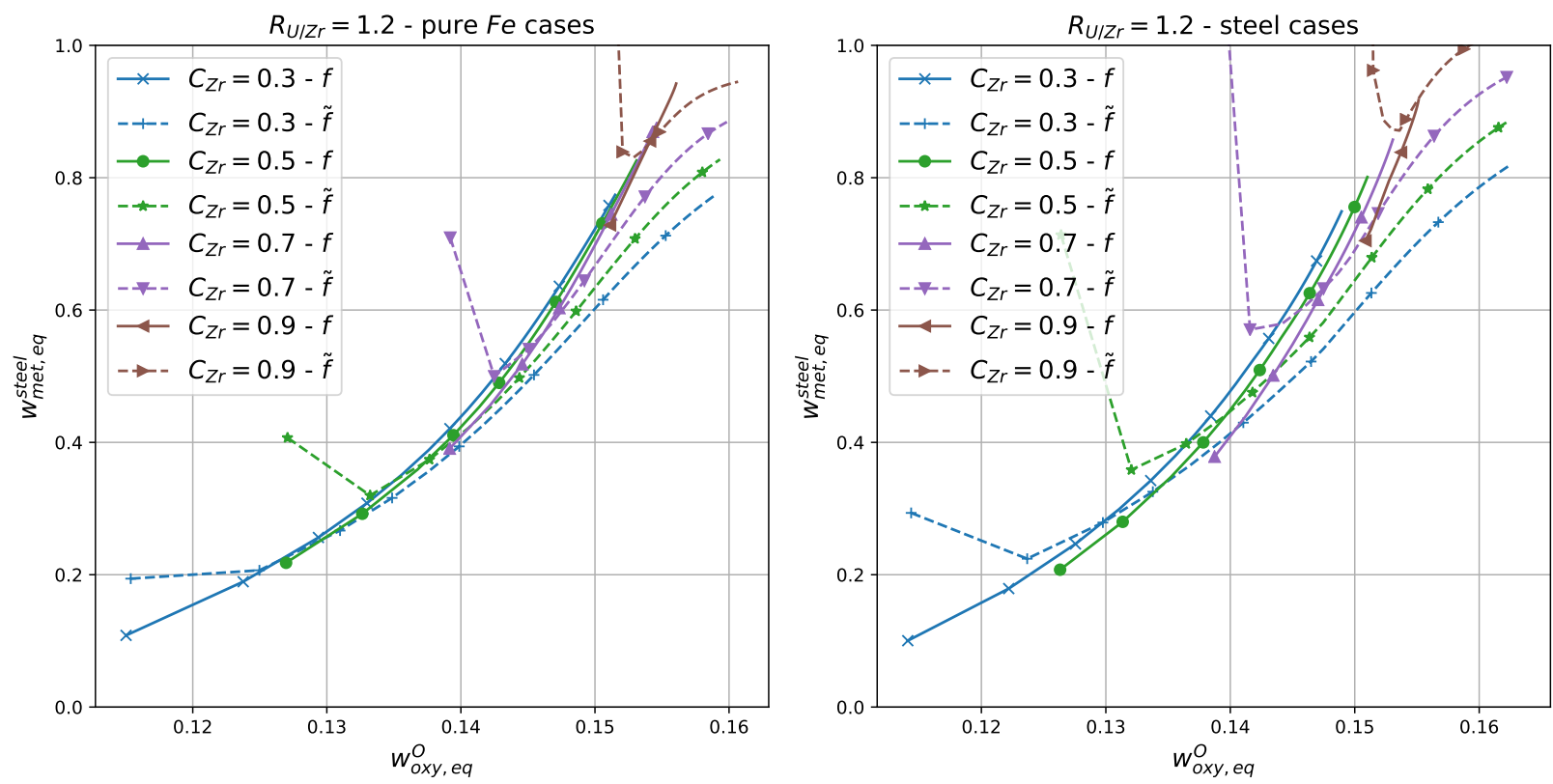

Figure 6: $f$ and $\tilde{f}$ functions $w_{o x y, e q}^{O} \mapsto w_{m e t, e q}^{\text {steel }}$ for $R_{U / Z r}=1.2$ and $C_{Z r} \in\{0.3,0.5,0.7,0.9\}$

In the remainder, only simulations with stainless steel will be reported.

\subsection{Numerical simulations and analysis}

In this section, different numerical simulations are presented. They consist in both a partial verification of the models and an analysis of the trends in a limited parametric study.

More precisely, in Section 3.3.1, the validity of the thermodynamic closure for the interface condition Eq. 15 is discussed. The system composition in terms of $Z r$ oxidation degree and steel-to-corium mass ratio is varied in Section 3.3 .2 covering the range of interest for reactor accidental scenarios. In particular, considering $C_{Z r}$ between 0.3 and 0.9 adequately covers the range associated with both fast and slow core degradation kinetics. However, the reader should keep in mind that the oxide melt oxidation degree increases when it interacts with molten steel; as a consequence, the oxidation degree of the oxide layer in a stratified pool is expected to be larger than the oxidation degree of the suboxidized melt from the core degradation. Then, the impact of the initial droplet radius is discussed in Section 3.3.3 along variations of the model parameters associated with the droplet internal mass transfer. Finally, based on these results, Section 3.4 provides a posteriori comments on some of the model hypotheses.

\subsubsection{Thermodynamic closure ( $\tilde{f}$ vs. $f$ ) and mass transfer in the oxide phase (varying $S h_{\text {oxy }}$ )}

First of all, the two different ways of constructing the interface thermodynamic closure are compared. In Figure 7 the evolution of the masses and average mass fractions are depicted for both $\tilde{f}$ and $f$ closures and compared with the associated equilibrium values (evaluated by OpenCalphad). The set of parameters defining this test case is also summarised in Figure 7, note in particular that $r^{0}=1 \mathrm{~cm}$. This configuration corresponds to an equilibrium configuration with a metal phase heavier than the oxide one $\left(\rho_{\text {met,eq }}>\rho_{\text {oxy }, e q}\right)$. As expected, it can be observed that using $\tilde{f}$ the phase partition at equilibrium is enforced while with $f$, a limited discrepancy associated with $\mathrm{H} 5$ and $\mathrm{H} 6$ can be observed. From the point of view of the accuracy on stationary values, the use of $\tilde{f}$ could be favoured. In addition, on the specific test case of Figure 7 , limited differences between the simulations based on $f$ and $\tilde{f}$ are observed during the transient. 

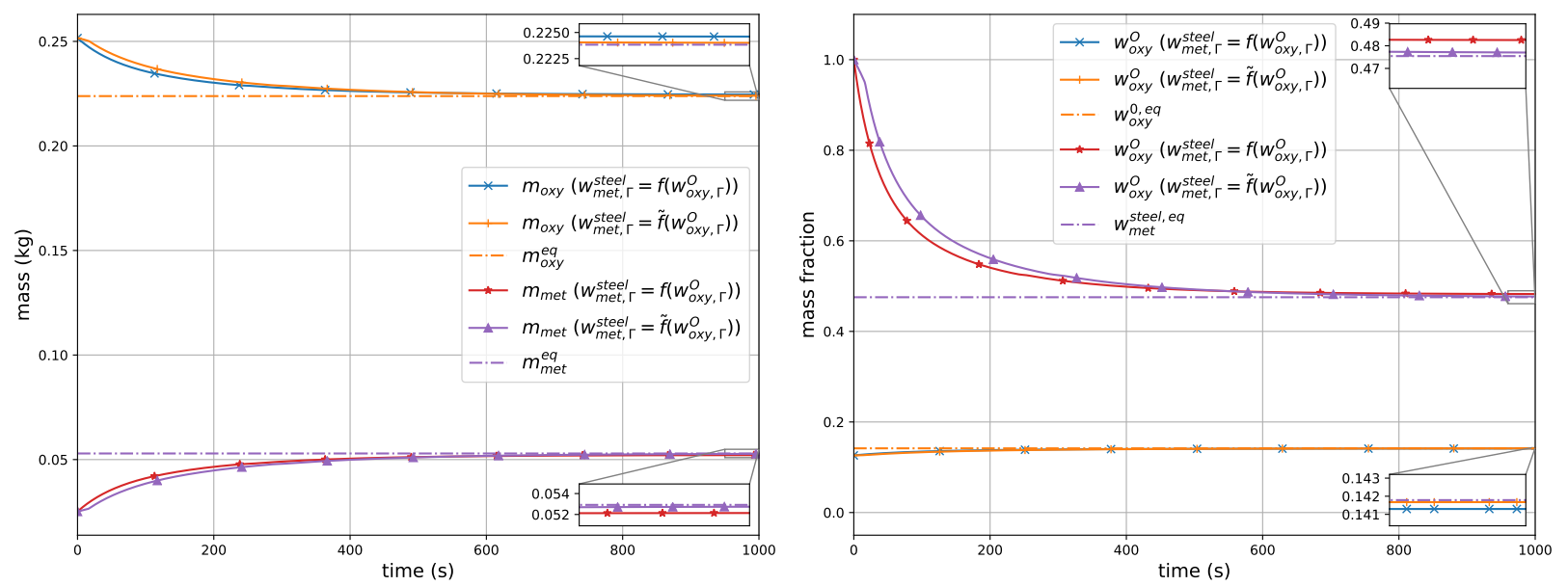

\begin{tabular}{|c|c|c|c|c|}
\hline$R_{U / Z r}=1.2$ & $x_{\text {steel }}=0.1$ & $\tilde{f}$ or $f$ & $D_{\text {oxy }}=5 \cdot 10^{-9} \mathrm{~m}^{2} \cdot \mathrm{s}^{-1}$ & $D_{\text {met }}=5 \cdot 10^{-9} \mathrm{~m}^{2} \cdot \mathrm{s}^{-1}$ \\
$C_{Z r}=0.5$ & $r^{0}=10^{-2} \mathrm{~m}$ & & $S h_{\text {oxy }}=2 \cdot 10^{3}$ & $S h_{\text {met }}:$ Juncu 2010 \\
\hline
\end{tabular}

Figure 7: Evolution of $m_{\text {oxy }}, m_{m e t}, w_{o x y}^{O}$ and $w_{m e t}^{\text {steel }}$ towards equilibrium with $\tilde{f}$ or $f-\left(\rho_{m e t, e q}>\rho_{\text {oxy }, e q}\right)$

However, as illustrated in Figure 8 for $r^{0}=0.1 \mathrm{~cm}$ and varying $S h_{o x y}$, the differences between $f$-based and $\tilde{f}$-based simulations can be larger depending on the configuration parameters (in this case when decreasing $r^{0}$ or increasing $S h_{o x y}$ ). Actually, when comparing, $S h_{o x y}=10^{3}$ and $S h_{o x y}=10^{4}$ results, $\tilde{f}$-based calculations appear as inconsistent as a higher mass transfer coefficient in the oxide leads to a delay in the overall mass transfer from the oxide to the metal. With $f$ closure, results are consistent. When looking in more details at the evolution of the interface mass fractions, it becomes clear that for $r^{0}=0.1 \mathrm{~cm}$ (as opposed to $r^{0}=1 \mathrm{~cm}$ in Figure 7), using $\tilde{f}$ entails nonphysical results with a non-monotonous behaviour of $w_{m e t, \Gamma}^{\text {steel }}$ that can be traced back to the non-monotonicity of $\tilde{f}$ previously discussed. Indeed, for $R_{U / Z r}=1.2$ and $C_{Z r}=0.5$, as seen on Figure 6 for the stainless steel case, when $w_{o x y, \Gamma}^{O}$ is below (resp. above) $\approx 0.1325, w_{m e t, \Gamma}^{\text {steel }}$ decreases (resp. increases). Consistently, in Figure 8 it is around this threshold value of about 0.1325 for $w_{o x y, \Gamma}^{O}$ that $w_{m e t, \Gamma}^{\text {steel }}$ variation is reversed.

Because of this possible nonphysical behaviour associated with $\tilde{f}, f$ will be used in the remainder taking into account that, in any case, the induced discrepancy on stationary values is limited and compatible with the goal of this "first-order" analysis.

Finally, going back to the results presented on Figure 8 for $f$, it can be seen that the impact of varying $S h_{\text {oxy }}$ by one order of magnitude (from $10^{4}$ to $10^{3}$ ) does not have a first-order effect on the transient. Indeed, with $D_{m e t}=5 \cdot 10^{-9} \mathrm{~m}^{2} \cdot \mathrm{s}^{-1}$ and $S h_{m e t}$ set to Juncu2010, it is the mass transfer in the metal phase that limits the overall kinetics. 

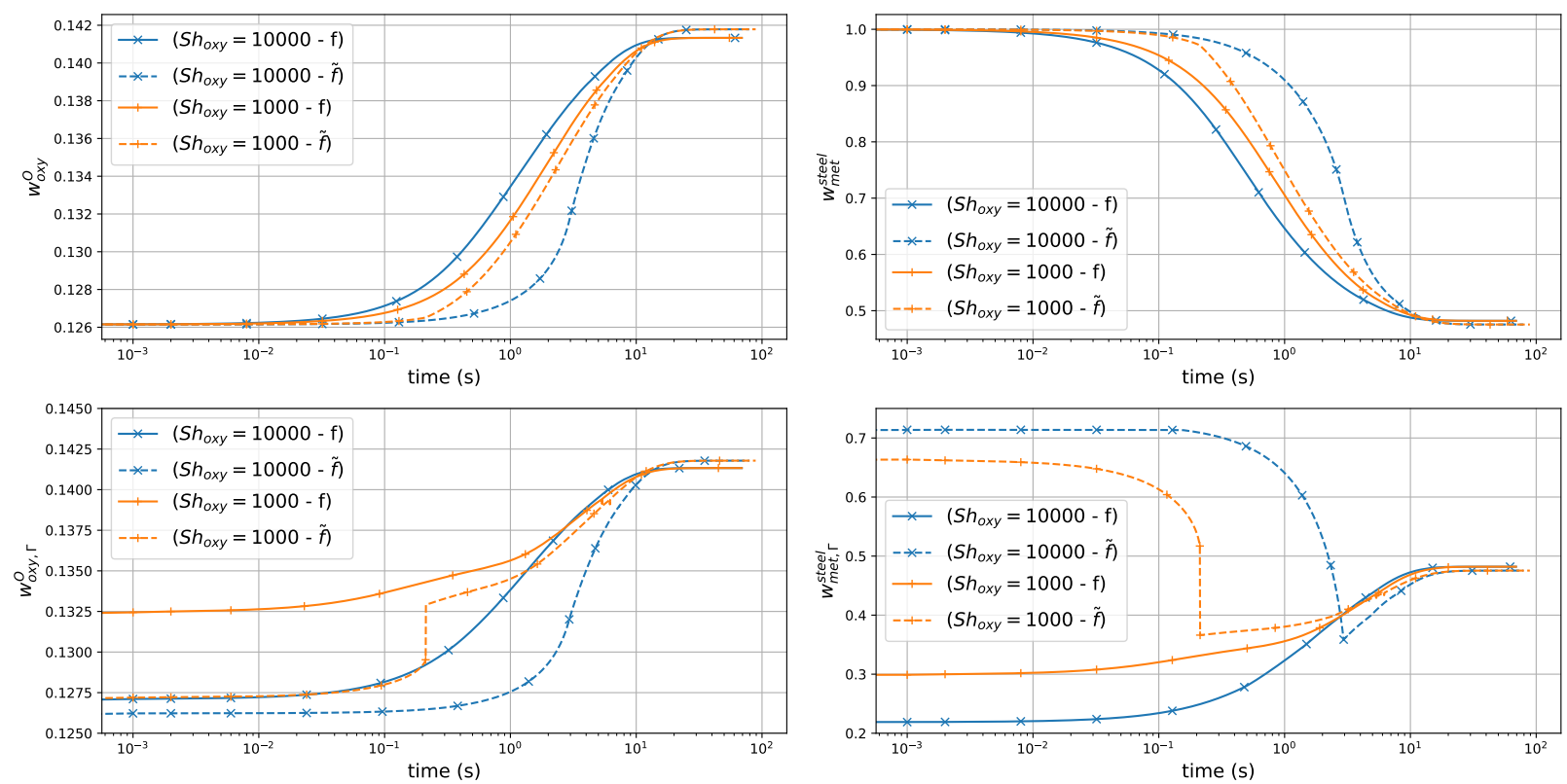

\begin{tabular}{|c|c|c|c|c|}
\hline$R_{U / Z r}=1.2$ & $x_{\text {steel }}=0.1$ & $\tilde{f}$ or $f$ & $D_{\text {oxy }}=5 \cdot 10^{-9} \mathrm{~m}^{2} \cdot \mathrm{s}^{-1}$ & $D_{\text {met }}=5 \cdot 10^{-9} \mathrm{~m}^{2} \cdot \mathrm{s}^{-1}$ \\
$C_{Z r}=0.5$ & $r^{0}=10^{-3} \mathrm{~m}$ & & $S h_{\text {oxy }} \in\left\{10^{3}, 10^{4}\right\}$ & $S h_{\text {met }}:$ Juncu2010 \\
\hline
\end{tabular}

Figure 8: Evolution of $w_{m e t}^{\text {steel }}, w_{o x y}^{O}, w_{o x y, \Gamma}^{O}$ and $w_{m e t, \Gamma}^{\text {steel }}$ when varying $S h_{o x y}$ with $\tilde{f}$ or $f-\left(\rho_{m e t, e q}>\rho_{o x y, e q}\right)$

\subsubsection{Phase partition as a function of $x_{\text {steel }}$ and $C_{Z r}$}

In Figure 9 (resp. Figure 10), different simulations are compared when varying $x_{\text {steel }}$ (resp. $C_{Z r}$ ) in terms of mass fractions, metal mass and droplet radius as a function of time. Note that these simulations cover cases where the metal phase at equilibrium is heavier or lighter than the oxide one. The trends obtained in these simulations on phase partitioning at steady-state can be readily compared with equilibrium results in order to assess the model consistency.

As expected, the lower $x_{\text {steel }}$ or $C_{Z r}$ are, the higher the mass transfer from the oxide to the metallic droplet is. Indeed, at thermodynamic equilibrium, the metal phase enrichment in $U$ and $Z r$ is higher when $x_{\text {steel }}$ or $C_{Z r}$ are lower. Regarding the characteristic time associated with this mass transfer, a lower $x_{\text {steel }}$ value leads to a longer transient while $C_{Z r}$ affects only marginally the duration of the transient (that slightly increases when $C_{Z r}$ increases). 

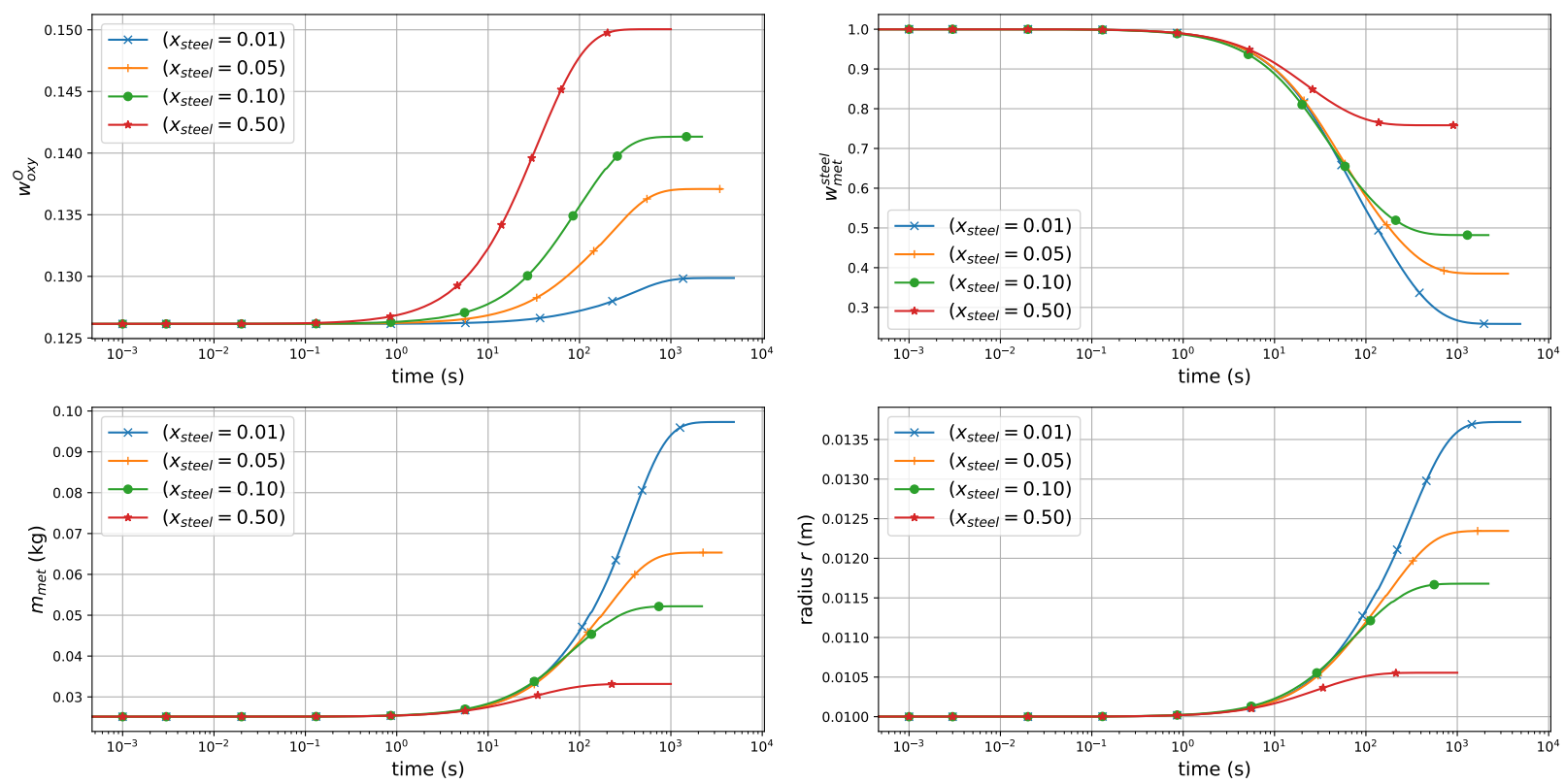

\begin{tabular}{|c|c|c|c|c|}
\hline$R_{U / Z r}=1.2$ & $x_{\text {steel }} \in\{0.01,0.05,0.1,0.5\}$ & $f$ & $D_{\text {oxy }}=5 \cdot 10^{-9} \mathrm{~m}^{2} \cdot \mathrm{s}^{-1}$ & $D_{\text {met }}=5 \cdot 10^{-9} \mathrm{~m}^{2} . \mathrm{s}^{-1}$ \\
$C_{Z r}=0.5$ & $r^{0}=10^{-2} \mathrm{~m}$ & & $S h_{\text {oxy }}=2 \cdot 10^{3}$ & $S h_{\text {met }}:$ Juncu 2010 \\
\hline
\end{tabular}

Figure 9: Evolution of $w_{\text {oxy }}^{O}, w_{\text {met }}^{\text {steel }}, m_{\text {met }}$ and the droplet radius when varying $x_{\text {steel }}-\left(\rho_{\text {met,eq }}>\rho_{\text {oxy }}\right.$ eq $)$ for $x_{\text {steel }} \in$ $\{0.01,0.05,0.1\},\left(\rho_{\text {met }, e q}<\rho_{\text {oxy }, e q}\right)$ for $x_{\text {steel }} \in\{0.5\}$

Interestingly, in both cases, a high mass transfer associated with low $x_{\text {steel }}$ and $C_{Z r}$ values significantly increases the droplet radius (e.g. $+37 \%$ in the $C_{Z r}=0.5, x_{\text {steel }}=0.01$ case of Figure 9). As the droplet radius plays a first-order role on its dynamics (as discussed in more details in the next section), this coupling is an important feature of the present model. 

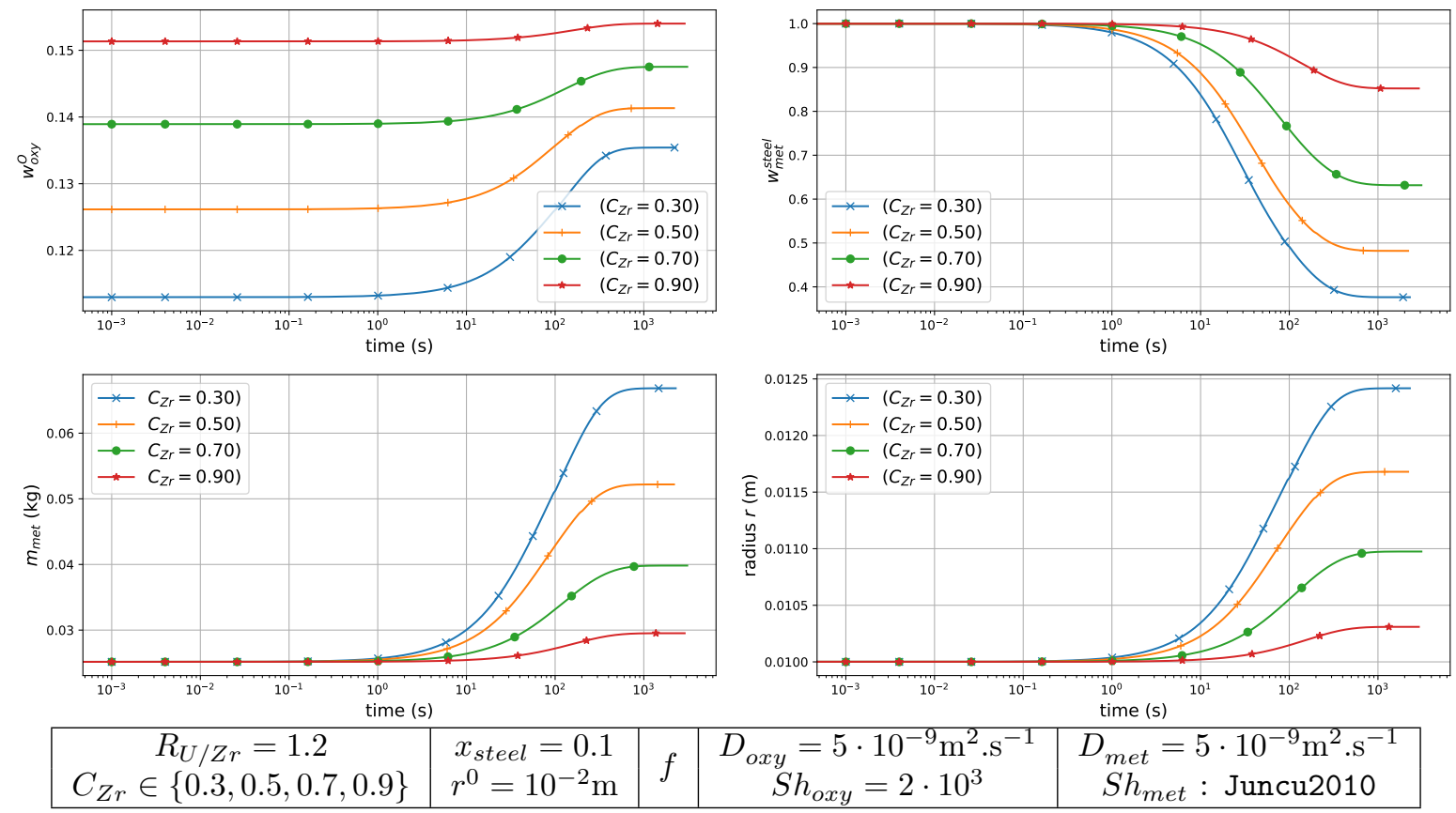

Figure 10: Evolution of $w_{o x y}^{O}, w_{m e t}^{\text {steel }}, m_{m e t}$ and the droplet radius when varying $C_{Z r}-\left(\rho_{m e t, e q}>\rho_{o x y, e q}\right)$ for $C_{Z r} \in\{0.3,0.5\}$, $\left(\rho_{\text {met }, e q}<\rho_{\text {oxy }, e q}\right)$ for $C_{Z r} \in\{0.7,0.9\}$

\subsubsection{Phase partition and droplet dynamics as a function of $r^{0}, S h_{m e t}$ and $D_{m e t}$}

In this section, the coupling between mass transfer and droplet dynamics is discussed.

First of all, $r^{0}$ is varied in $\{0.1,1,5\} \mathrm{cm}$ and, as expected and illustrated in Figure 11 through the evolution of the metal phase relative mass and steel mass fraction, the mass transfer kinetics is largely affected (the smaller $r^{0}$ is, the faster the transient is). At first-order, mass and mass fractions profiles for the different $r^{0}$ values, when plotted in logarithmic scale in Figure 11, look very similar with a shift in time associated with the increase of $r^{0}$.
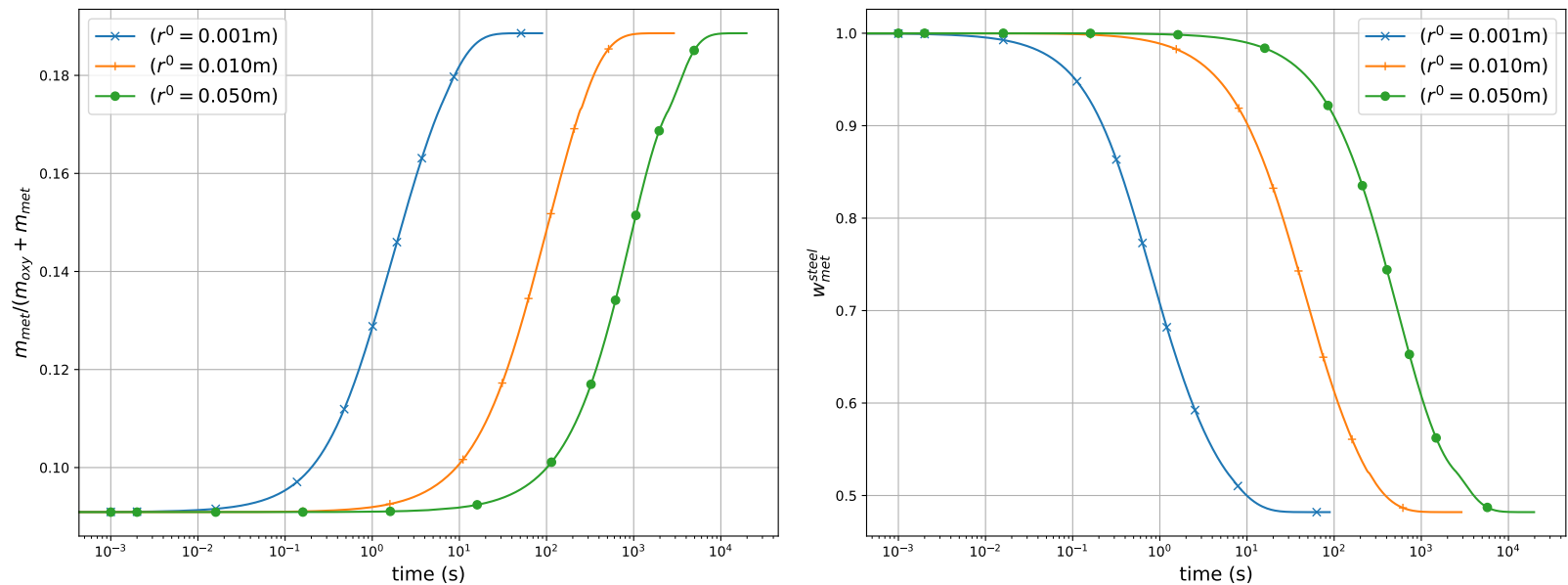

\begin{tabular}{|c|c|c|c|c|}
\hline$R_{U / Z r}=1.2$ & $x_{\text {steel }}=0.1$ & $f$ & $D_{\text {oxy }}=5 \cdot 10^{-9} \mathrm{~m}^{2} \cdot \mathrm{s}^{-1}$ & $D_{\text {met }}=5 \cdot 10^{-9} \mathrm{~m}^{2} \cdot \mathrm{s}^{-1}$ \\
$C_{Z r}=0.5$ & $r^{0} \in\{0.1,1,5\} \mathrm{cm}$ & & $S h_{\text {oxy }}=2 \cdot 10^{3}$ & $S h_{\text {met }}:$ Juncu2010 \\
\hline
\end{tabular}

Figure 11: Evolution of the metal phase relative mass and $w_{m e t}^{\text {steel }}$ when varying $r^{0}-\left(\rho_{\text {met, }, \text { q }}>\rho_{\text {oxy }, e q}\right)$ 
However, when looking more carefully at the mass transfer process, noticeable differences can be seen. In Figure 12, the evolution of the metal droplet Sherwood number $S h_{\text {met }}$ is shown for the different $r^{0}$ values. In all cases, in the first millisecond of the transient, $S h_{m e t}$ rapidly increases from its initial value $S h_{\text {met }}\left(R e_{\text {met }}=0, P e_{\text {met }}=0\right)=\frac{2 \pi^{2}}{3} \approx 6.58$ (associated with $v_{z}(t=0)=0$ ). Then, it continues to increases more slowly until a maximum. For $r^{0} \in\{1,5\} \mathrm{cm}$, this maximum value is followed by very slowly decreasing plateau. In this first part of the transient, mass transfer is still negligible in such a way that this maximum value is associated with pure-steel droplet reaching its terminal (ascending) velocity $v_{z}^{\infty}$ that can be defined as:

$$
v_{z}^{\infty}=\sqrt{\frac{2 V_{m e t}}{C_{D} S_{\perp}}\left|\frac{\rho_{\text {oxy }}-\rho_{m e t}}{\rho_{\text {met }}}\right| g}
$$

This can clearly be observed in Figure 12. Afterwards, $v_{z}$ decreases in a quasi-static way i.e. $v_{z}(t)$ is almost equal to the instantaneous value of $v_{z}^{\infty}$. For $r^{0}=0.1 \mathrm{~cm}$, mass transfer becomes important before the pure-steel terminal velocity is reached so that no plateau is observed for $S h$ that decreases right after its maximum has been reached. In all cases, as $\rho_{\text {met }}$ increases due to mass transfer, $v_{z}$ decreases until crossing 0 i.e. the ascending droplet has become heavier than the oxide and start descending. The instant when $v_{z}=0$ correspond to the downward spikes for $S h$ on Figure $12^{3}$ The period of time where $S h$ is small when $v_{z}$ changes sign is very limited for $r^{0} \in\{0.1,1\} \mathrm{cm}$ and becomes noticeable only for $r^{0}=5 \mathrm{~cm}$.

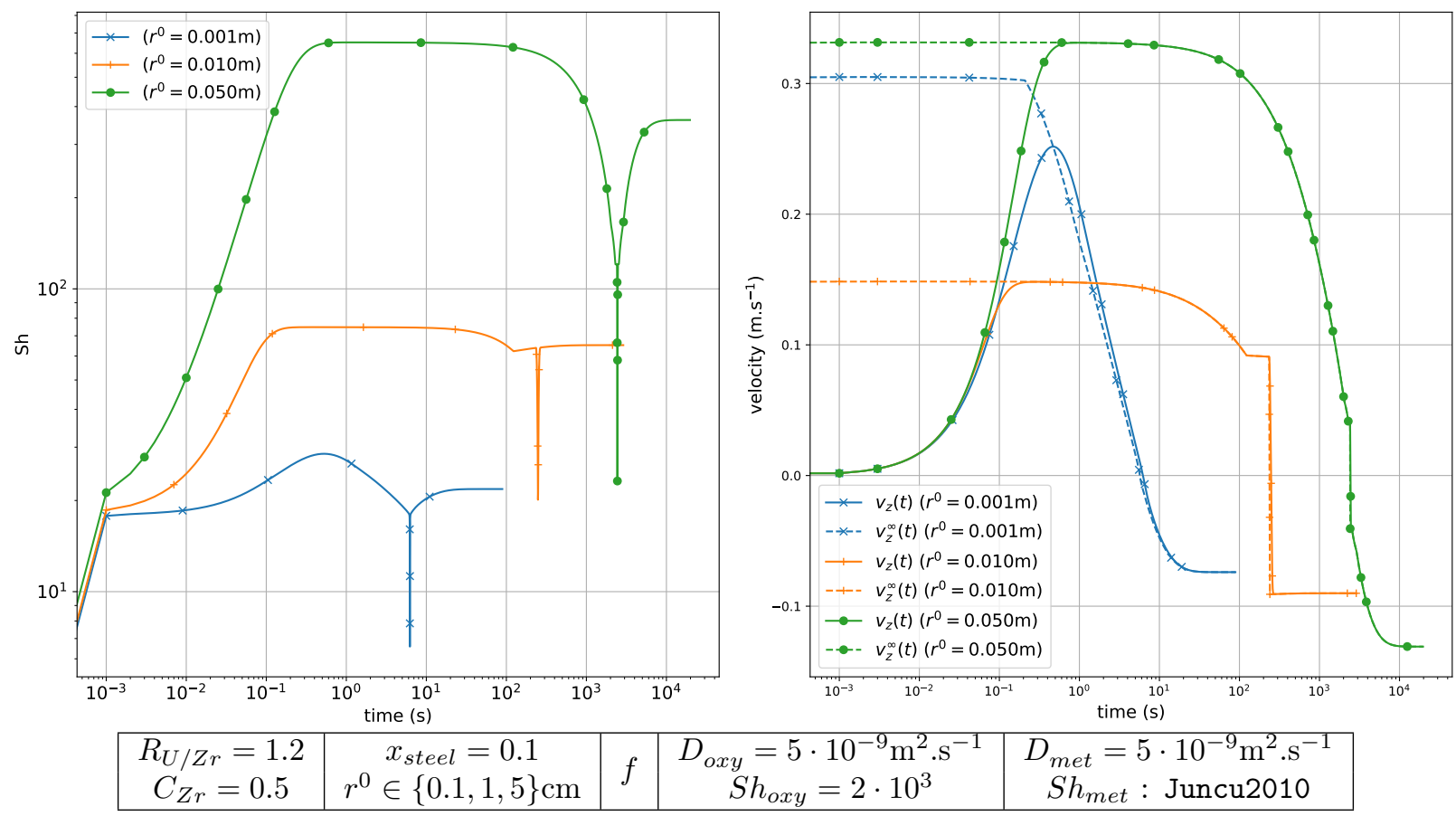

Figure 12: Evolution of $S h_{m e t}$, dimensionless number and velocity $v_{z}$ when varying $r^{0}-\left(\rho_{m e t, e q}>\rho_{\text {oxy }}, e q\right)$

The order of magnitudes difference on $S h_{m e t}$ when $r^{0}$ is varied are associated with large differences on the dimensionless numbers that come into play in the mass transfer correlation or the drag coefficient. In Figure 13, the evolution of $R e_{m e t}, E o$ and $W e$ are depicted for these same transient calculations. Note that $P e_{m e t}=S c_{m e t} R e_{m e t}$ follows a very similar trend as $R e_{m e t}$ as the Schmidt number $S c_{m e t}=\frac{\nu_{m e t}}{D_{m e t}}$ only slowly decreases during the transient (when $\rho_{\text {met }}$ increases) from $\approx 166.9$ to 142.3 . As previously discussed in Section 2.4. $R e_{m e t}$ and $P e_{m e t}$ covers a very wide range of values for $r^{0} \in\{0.1,1\} \mathrm{cm}$. Only the $r^{0}=0.1 \mathrm{~cm}$

\footnotetext{
${ }^{3}$ Because of the $y$-axis logarithmic scale of Figure 12 , when $S h \rightarrow 0$, values are not shown.
} 
case remains close to the definition domain of the Juncu2010 correlation used so far in these simulations. Accordingly, when comparing the Weber number to the critical values associated with Eqs. 20 and 21, it can be seen that the spherical regime is ensured only for $r^{0}=0.1 \mathrm{~cm}$.
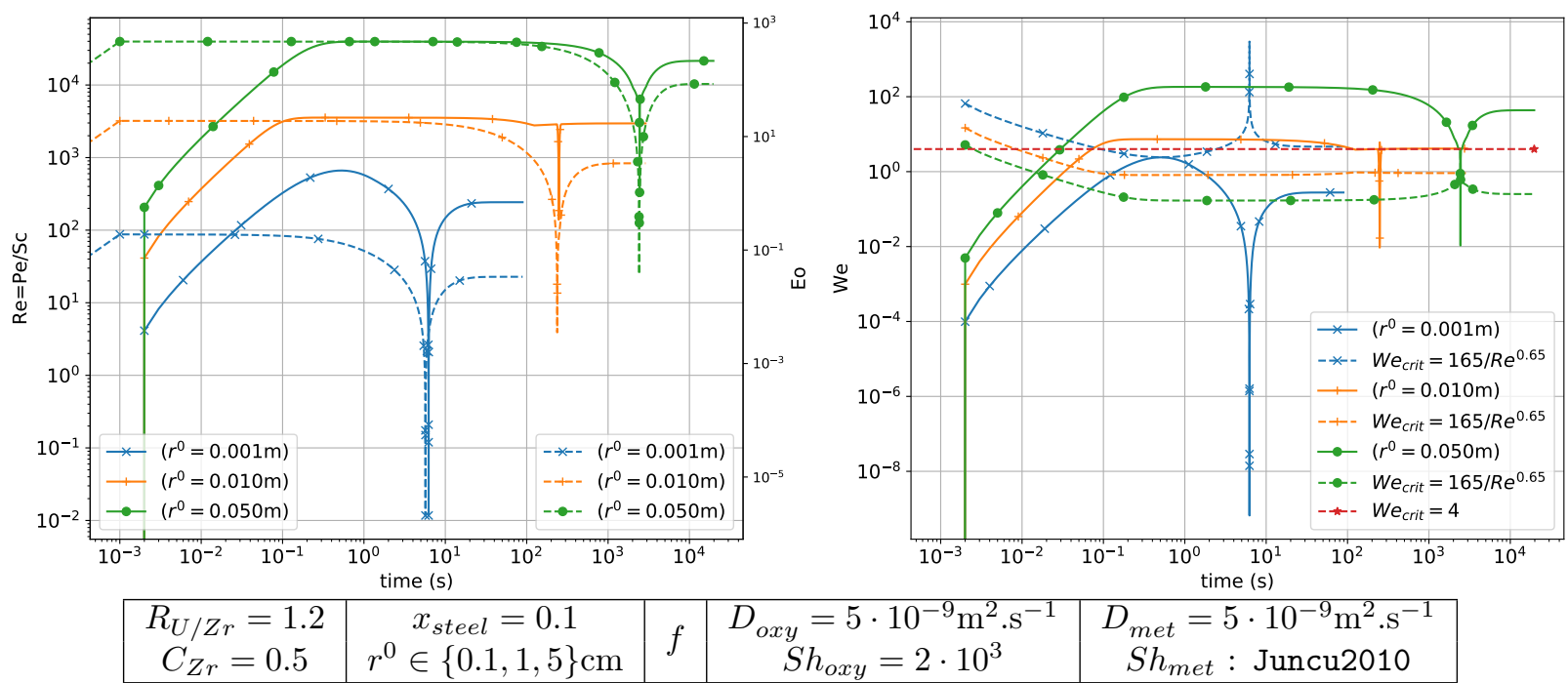

Figure 13: Evolution of $R e_{m e t}=P e_{m e t} / S c, E o$ and $W e$ dimensionless numbers when varying $r^{0}-\left(\rho_{m e t, e q}>\rho_{\text {oxy }, e q}\right)$

In our implementation of this model, the movement of the droplet is not restricted by the overall height of the oxide pool (in other words, the geometrical pattern consisting of a single droplet surrounded a given amount of oxidic corium is supposed to be repeated infinitely). However, one can calculate the time evolution of the droplet position by $z(t)=\int_{0}^{t} v_{z}(t) d t+z_{0}$ and compare it with the position of the oxidic pool boundaries a posteriori. Taking $z_{0}=0$, the droplet position in simulations where $r^{0}$ is varied is shown in Figure 14 Clearly, when $r^{0} \in\{1,5\} \mathrm{cm}$, the droplet rises in the oxide very rapidly and, in the practical reactor situation (with an oxidic pool height up to $\approx 2 \mathrm{~m}$ ), the mass transfer from the oxide cannot prevent the droplet to reach the oxide upper boundary (where it will form a continuous metal phase). It is only in the $r^{0}=0.1 \mathrm{~cm}$ case that mass transfer is sufficiently fast so that, depending on the oxide pool height, configurations where the droplets will become heavier than the oxide before it reaches its upper surface can occur. In this case, after a few tens of second in the oxide phase, the droplets would form a continuous heavy metal phase at the bottom of the oxide pool. 


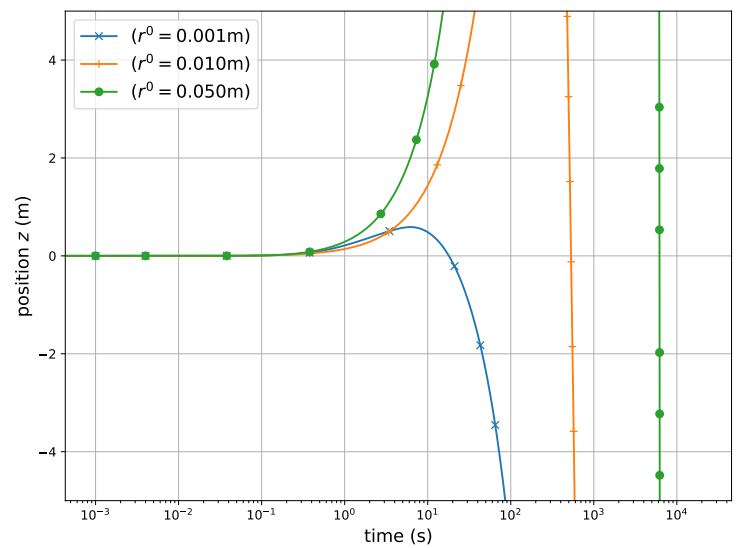

\begin{tabular}{|c|c|c|c|c|}
\hline$R_{U / Z r}=1.2$ & $x_{\text {steel }}=0.1$ & $f$ & $D_{\text {oxy }}=5 \cdot 10^{-9} \mathrm{~m}^{2} \cdot \mathrm{s}^{-1}$ & $D_{\text {met }}=5 \cdot 10^{-9} \mathrm{~m}^{2} \cdot \mathrm{s}^{-1}$ \\
$C_{Z r}=0.5$ & $r^{0} \in\{0.1,1,5\} \mathrm{cm}$ & $f$ & $S h_{\text {oxy }}=2 \cdot 10^{3}$ & $S h_{\text {met }}:$ Juncu2010 \\
\hline
\end{tabular}

Figure 14: Evolution of position $z$ when varying $r^{0}-\left(\rho_{m e t, e q}>\rho_{o x y, e q}\right)-$ the $y$-axis range has been truncated

So far, we have used $D_{m e t}=5 \cdot 10^{-9} \mathrm{~m}^{2} \cdot \mathrm{s}^{-1}$ and $S h_{m e t}$ calculated by Juncu2010 correlation. In a last set of numerical results, higher droplet mass transfer has been investigated considering $D_{\text {met }} \in$ $\left\{5 \cdot 10^{-9}, 5 \cdot 10^{-8}\right\} \mathrm{m}^{2} \cdot \mathrm{s}^{-1}$ and both Juncu2010 and Wegener2014 for $S h_{m e t}$ evaluation. Two values of the droplet initial radius were considered $\left(r^{0} \in\{0.1,0.5\} \mathrm{cm}\right)$ while $S h_{o x y}$ was increased from $2 \cdot 10^{3}$ to $10^{4}$ so that the overall mass transfer is always limited by the droplet internal mass transfer. These results are presented in terms of droplet velocity and position in Figure 15

As expected, when the intra-droplet mass transfer is faster (i.e. when $D_{m e t}$ and $S h_{m e t}$ are higher), the initial ascension of the light metal droplet is more limited in such a way that it may be possible (in some configurations) for droplets of initial radius $r^{0}=0.5 \mathrm{~cm}$ to directly form a heavy metal phase at the bottom of the oxide pool. Note that the impact of selecting Juncu2010 or Wegener2014 (two very different correlations as discussed in Section 2.4 with Figure 3) is more important when a smaller value of $D_{\text {met }}$ is considered. Considering only the $D_{\text {met }}=5 \cdot 10^{-8} \mathrm{~m}^{2} \cdot \mathrm{s}^{-1}$ case, the evolution of $W e$ is shown in Figure 16 along with its comparison with the critical values associated with Eqs. 20 and 21. It can be seen as before that the spherical regime seems ensured for $r^{0}=0.1 \mathrm{~cm}$ while, for $r^{0}=0.5 \mathrm{~cm}$, the droplet regime is somewhat uncertain (in the sense that the criterion associated with Eq. 21 is met while the criterion of Eq. 20 is not) and one may assume that it is in a "transition" regime and exhibits limited deformation. 

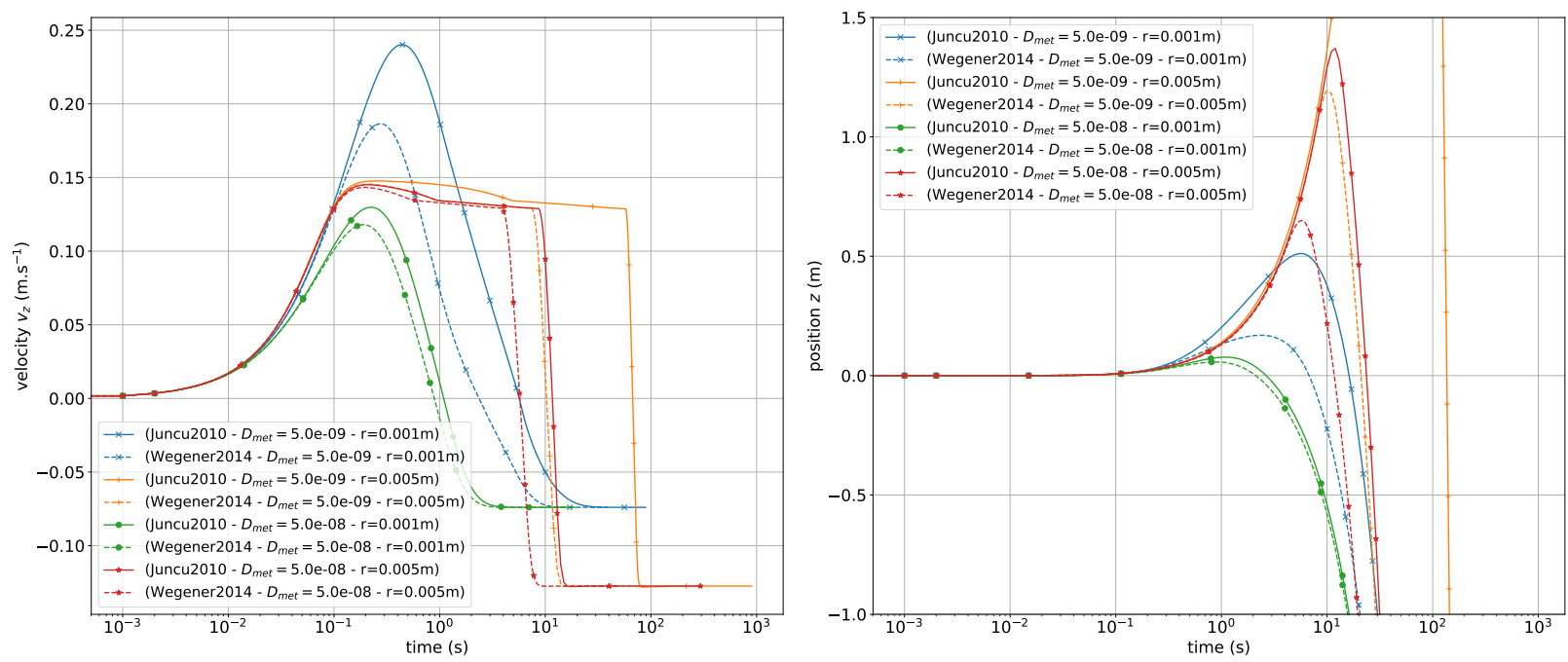

\begin{tabular}{|c|c|c|c|c|}
\hline$R_{U / Z r}=1.2$ & $x_{\text {steel }}=0.1$ & $f$ & $D_{\text {oxy }}=5 \cdot 10^{-9} \mathrm{~m}^{2} \cdot \mathrm{s}^{-1}$ & $D_{\text {met }} \in\left\{5 \cdot 10^{-9}, 5 \cdot 10^{-8}\right\} \mathrm{m}^{2} \cdot \mathrm{s}^{-1}$ \\
$C_{Z r}=0.5$ & $r^{0} \in\{0.1,0.5\} \mathrm{cm}$ & $f$ & $S h_{\text {oxy }}=10^{4}$ & $S h_{\text {met }}:$ Juncu2010 or Wegener 2014 \\
\hline
\end{tabular}

Figure 15: Evolution of velocity $v_{z}$ and position $z$ when varying $r^{0}, S h_{m e t}$ and $D_{m e t}-\left(\rho_{m e t, e q}>\rho_{\text {oxy }, e q}\right)-$ the $y$-axis range has been truncated for the position

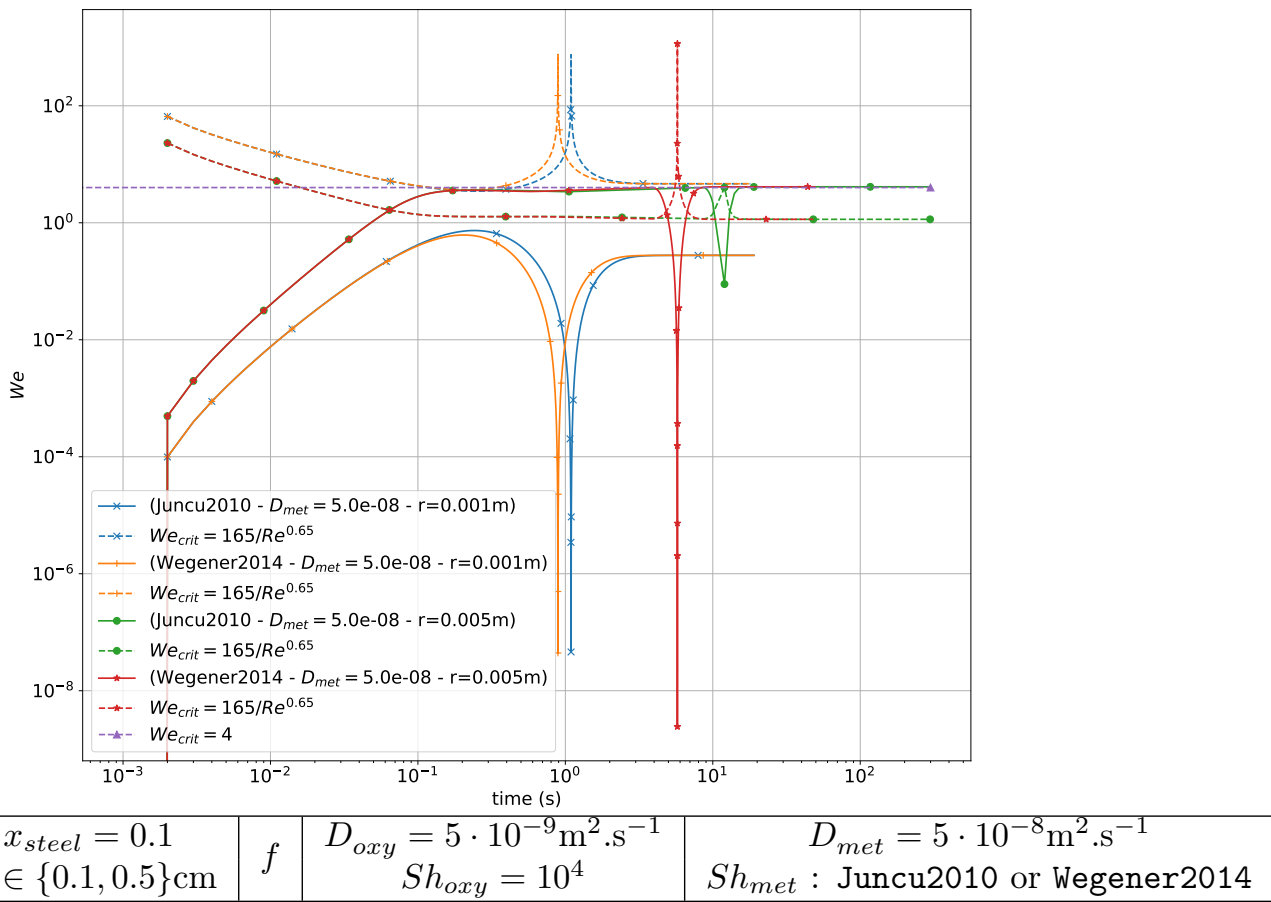

Figure 16: Evolution of We dimensionless number when varying $r^{0}, S h_{m e t}$ and $D_{m e t}-\left(\rho_{m e t, e q}>\rho_{\text {oxy }, e q}\right)$

\section{4. a posteriori comments on some modelling hypotheses}

Based on the analysis of these numerical results, let us come back on the model underlying hypotheses.

For H3 (thermal equilibrium), as discussed in Section 2, the characteristic time associated with intradroplet heat transfer $\tau_{H T}$ is, in any case, small in comparison with the mass transfer characteristic time 
$\tau_{M T}$. When the droplet radius increases, $\tau_{H T}$ increases in such a way that for "large" steel droplets, $\tau_{H T}$ can become comparable to the droplet travel time through the oxide (this is the case for $r^{0}=5 \mathrm{~cm}$ if the Juncu2010 correlation is considered). Accordingly, in principle, for "large" droplets, heat transfer would have to be modelled. However, in the reactor case, the oxide melt undergoes turbulent convection that will have an impact on the droplet size; as such, a 10-cm diameter droplet may be considered as very unlikely in the reactor case in the sense that the deformation of such a large droplet could lead to its fragmentation into smaller ones.

Regarding H2 (stagnant oxide phase), the droplet velocities can be compared with the typical velocities in an homogeneous pool under natural convection (as illustrated in Figure 17). In addition to Figure 12 . the droplet velocity evolution is shown for the previously introduced cases where $x_{\text {steel }}$ or $C_{Z r}$ are varied in Figure 18 Considering a droplet terminal velocity of $0.1 \mathrm{~m} . \mathrm{s}^{-1}$, we can see that it is about 2 (resp. 5) times larger than the oxide velocity in the recirculating zone along the lateral boundary of the pool (resp. in the upper region associated with the convection rolls). As a consequence, the impact of the RayleighBénard rolls on the droplet movement can probably be neglected except in the narrow composition range near the stratification inversion threshold (i.e. when the droplet mass density is very close to the oxide one). The main possible impact of oxide momentum on the droplet movement is associated with the lateral recirculating region. Indeed, considering molten metal droplets coming from the vessel ablation, initially, they could be "pushed down" along the vessel wall by the oxide in such a way that their rise through the oxide would be "delayed". With the present integral model, this could be grossly taken into account by imposing an initial velocity to the droplet.

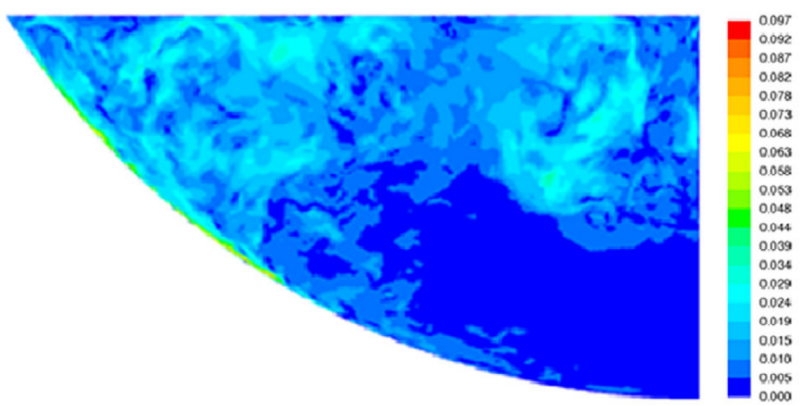

Figure 17: Computational Fluid Dynamics simulation of a BALI 31 experimental configuration using "Large Eddy Simulation" for turbulence - velocity modulus $\left(\mathrm{m} . \mathrm{s}^{-1}\right)$ - extracted from 32 


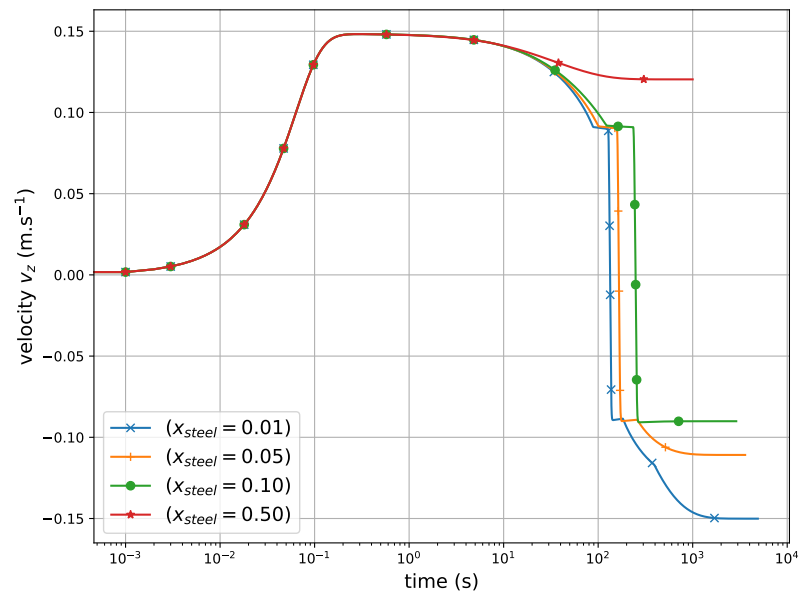

(a) $x_{\text {steel }} \in\{0.01,0.05,0.1,0.5\}-C_{Z r}=0.5$

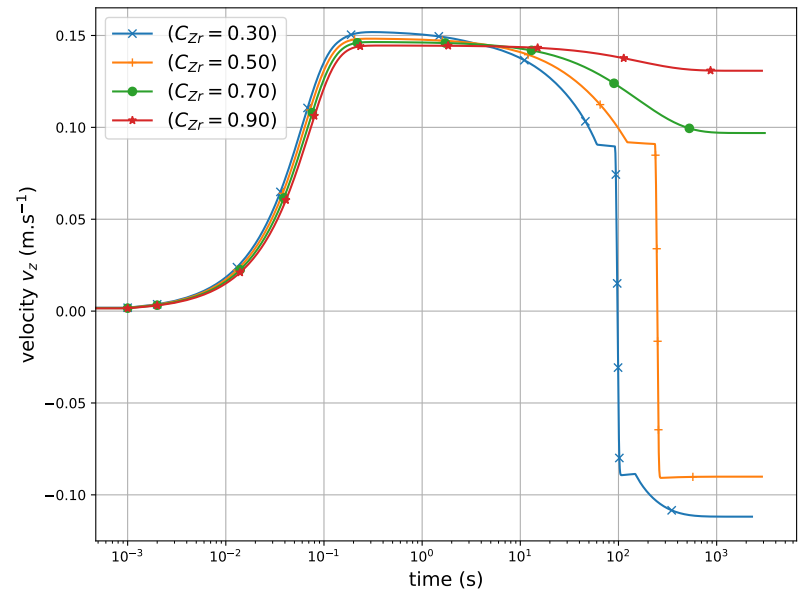

(b) $C_{Z r} \in\{0.3,0.5,0.7,0.9\}-x_{\text {steel }}=0.1$

$$
\begin{array}{|l|c|c|c|}
\hline R_{U / Z r}=1.2 & D_{o x y}=5 \cdot 10^{-9} \mathrm{~m}^{2} \cdot \mathrm{s}^{-1} & D_{\text {met }}=5 \cdot 10^{-9} \mathrm{~m}^{2} \cdot \mathrm{s}^{-1} \\
r^{0}=10^{-2} \mathrm{~m} & f & S h_{\text {oxy }}=2 \cdot 10^{3} & S h_{\text {met }}: \text { Juncu2010 } \\
\hline
\end{array}
$$

Figure 18: Evolution of velocity $v_{z}$ when varying $x_{\text {steel }}$ or $C_{Z r}$

Regarding H1 (isolated droplet), if droplet interaction effects can have a significant impact, evaluating them in the present application appear as complicated and requires additional knowledge about molten steel relocation "path" through the crust to the oxidic pool. For the question of the vessel wall molten steel relocation, such a $R \& D$ issue is of particular importance as a significant part of the mass transfer from the oxide pool to the metal phase can occur during the droplet formation.

\section{Conclusions}

An integral model describing mass transfer between a dispersed metallic phase and a continuous oxide phase, both in liquid state, has been proposed and implemented as a "mock-up" model in the PROCOR platform. Constructed on "first-order" simplifying hypotheses, this isothermal model that also describes the coupled metallic droplet motion, has been used in a limited parametric analysis regarding the behaviour of metal droplets in the oxidic melt. This situation of interest occurs when considering ablation of the lower head steel internal structures or the vessel wall by the oxide pool.

Consistently with the equilibrium conditions, the $U$ and $Z r$ content in the droplet at steady-state was found to increase when the initial $Z r$ oxidation degree $C_{Z r}$ or the steel-to-corium mass ratio $x_{\text {steel }}$ decrease. Accordingly, for low enough values of $C_{Z r}$ and/or $x_{\text {steel }}$, this increase can lead to a higher density than the oxide phase. In such a case, considering two different mass transfer correlations along with a variation by one order of magnitude of the effective diffusion coefficient of steel in the metal droplet, it was shown that mass transfer is likely to be fast enough in case of "small" (millimetric) droplets to induce relocation at the bottom of the pool. For larger droplets, a relocation to the top of the pool can be expected with lower $U$ and $Z r$ content in the droplet. The "mixing" of the metallic dispersed phase in the oxide can only be stable for a very limited compositional range near the density inversion threshold. Consequently, an homogeneous treatment of the molten metal incorporation in the oxide phase, as used in some in-vessel modelling, seems inadequate.

With respect to the lower plenum corium retention application, the main limitation of this analysis is that it is uncoupled from the mass transfer between the oxide phase and the continuous metal phase at the top or the bottom of a stratified pool. Completing this "first-order" analysis (including sensitivities to model parameters) and drawing more detailed conclusions regarding the practical reactor case (in terms of R\&D needs and mandatory - or not - codes enhancement) would require an extension to a stratified pool modelling. Actually, from the point of view of the interface mass tranfer modelling, such an extension could 
easily be made under the same simplifying hypotheses regarding the thermodynamic system. Such a model would then have to be supplemented by closures for the Rayleigh-Taylor induced droplets formation at the interface between the continous oxide and metal phases.

Finally, it is to be noted that going further than such a "first-order" analysis (e.g. taking into account droplet interactions) would require:

- additional knowledge about molten steel relocation "path" through the crust to the oxidic pool taking into account both thermochemistry (dissolution [33]) and thermomechanics (while the former is an "active" research theme, the latter remains to be explored);

- more detailed simulations at a finer scale using "Computational Fluid Dynamics" models (typically, the phase-field modelling under study for stratification kinetics [34]).

\section{Acknowledgements}

This work has been carried out within the framework of the PROCOR platform development funded by CEA, EDF and Framatome.

\section{References}

[1] T. G. Theofanous, C. Liu, S. Addition, S. Angelini, O. Kymalainen, T. Salimassi, In-vessel coolability and retention of a core melt, Nuclear Engineering and Design 169 (1997) 1-48 (1997).

[2] R. E. Henry, H. K. Fauske, External cooling of a reactor vessel under severe accident conditions, Nuclear Engineering and Design 139 (1) (1993) 31 - 43 (1993). doi:https://doi.org/10.1016/0029-5493(93)90260-G| URL http://www.sciencedirect.com/science/article/pii/002954939390260G

[3] D. F. Tsurikov, V. F. Strizhov, S. V. Bechta, V. N. Zagriazkin, N. P. Kiselev, Main results of MASCA1 and 2 projects, Tech. rep., RRC Kurchatov Institute (2007).

[4] F. Fichot, L. Carénini, R. Le Tellier, L. Viot, N. Bakouta, A. Filippov, Identification and evaluation of the remaining uncertainties for transient situations, in: Proc. of International Seminar "In-vessel retention: outcomes of IVMR project", Juan-les-Pins, France, 2020 (January 2020).

[5] R. Le Tellier, L. Viot, L. Carénini, F. Fichot, N. Bakouta, A. Filippov, Transient stratified corium pool modelling for invessel retention analysis, in: Proc. of International Seminar "In-vessel retention: outcomes of IVMR project", Juan-les-Pins, France, 2020 (January 2020).

[6] R. Le Tellier, B. Habert, V. Tiwari, N. Bakouta, Consistent use of CALPHAD data for in-vessel corium pool modeling: some analytical and practical considerations, in: Proc. of the 9th European Review Meeting on Severe Accident Research ERMSAR2019, Prague, Czech Republic, 2019 (2019).

[7] A. Borgenstam, L. Höglund, J. Ågren, A. Engström, DICTRA, a tool for simulation of diffusional transformations in alloys., Journal of Phase Equilibria (21) (2000) 269-280 (2000).

[8] H. Larsson, A model for 1d multiphase moving phase boundary simulations under local equilibrium conditions, CALPHAD: Computer Coupling of Phase Diagrams and Thermochemistry (47) (2014) 1-8 (2014).

[9] V. Tiwari, A consistent approach for coupling lumped-parameter and phase-field models for in-vessel corium to thermodynamic databases, Ph.D. thesis, Université Paris-Saclay (2019).

[10] M. Salay, F. Fichot, Modelling of metal-oxide corium stratification in the lower plenum of a reactor vessel, in: Proc. of Int. Topical Meeting on Nuclear Thermal-Hydraulics (NURETH-11), Avignon, France, 2005 (2005).

[11] S. Nandan, F. Fichot, B. Piar, A simplified model for the quaternary u-zr-fe-o system in the miscibility gap, Nuclear Engineering and Design 364 (2020) 110608 (2020).

[12] J. M. Seiler, K. Froment, J. P. Garandet, Equations for solidification of corium without sparging gas - scaling criteria, in: Proc. of OECD Workshop on Ex-Vessel Debris Coolability, OECD, Karlsruhe, Germany, 1999 (1999).

[13] G. Juncu, A numerical study of the unsteady heat/mass transfer inside a circulating sphere, International Journal of Heat and Mass Transfer 53 (2010) 3006-3012 (2010).

[14] D. Colombet, D. Legendre, A. Cockx, P. Guiraud, Mass and heat transfer inside a spherical gas bubble at low to moderate reynolds number, International Journal of Heat and Mass Transfer 67 (2013) 1096-1105 (2013).

[15] D. Legendre, On the relation between the drag and the vorticity produced on a clean bubble, Physics of Fluids 19 (018102) (2007).

[16] M. Wegener, N. Paul, M. Kraume, Fluid dynamics and mass transfer at single droplet in liquid/liquid systems, International Journal of Heat and Mass Transfer 71 (2014) 475-495 (2014).

[17] A. Kumar, S. Hartland, Correlations for prediction of mass transfer coefficients in single drop systems and liquid-liquid extraction columns, Transactions IChemE 77 (A) (1999) 372-384 (1999).

[18] C. Cardon, Modélisation de la diffusion multi-composants dans un bain de corium diphasique oxyde-métal par une méthode d'interface diffuse, Ph.D. thesis, Université Paris-Saclay (2016). 
[19] L. A. Girifalco, R. J. Good, A theory for the estimation of surface and interfacial energies. I. Derivation and application to interfacial tension, The Journal of Physical Chemistry 61 (7) (1957) 904-909 (1957).

[20] G. A. Greene, T. F. Irvine, T. Gyves, T. Smith, Drag relationships for liquid droplets settling in a continuous liquid, AIChE Journal 39 (1) (1993) 37-41 (1993).

[21] G. B. Wallis, The terminal speed of single drops or bubble in an infinite medium, International Journal of Multiphase Flow 1 (1974) 491-511 (1974).

[22] P. Di Marco, W. Grassi, G. Memoli, Experimental study of rising velocity of nitrogen bbubble in FC-72, International Journal of Thermal Sciences 42 (2003) 435-446 (2003).

[23] R. Le Tellier, L. Saas, F. Payot, Phenomenological analyses of corium propagation in LWRs: the PROCOR software platform, in: Proc. of the 7th European Review Meeting on Severe Accident Research ERMSAR-2015, Marseille, France, 2015 (2015).

[24] C. Journeau, P. Piluso, K. N. Frolov, Corium physical properties for severe accident r\&d, in: Proc. of the 2004 international congress on advances in nuclear power plants - ICAPP'04, 2004 (2004).

[25] B. Spindler, B. Tourniaire, J. M. Seiler, Simulation of MCCI with the TOLBIAC-ICB code based on the phase segregation model, Nuclear Engineering and Design 236 (2006) 2264-2270 (2006).

[26] A. Y. Kupryazhkin, A. N. Zhiganov, D. V. Risovany, K. A. Nekrassov, V. D. Risovany, V. N. Golovanov, Simulation of diffusion of oxygen and uranium in uranium dioxide nanocrystals, Journal of Nuclear Materials 372 (2008) $233-238$ (Jan. 2008).

[27] B. Cheynet, P. Chevalier, E. Fischer, Thermosuite, Calphad 26 (2) (2002) 167-174 (2002).

[28] S. Bakardjieva, M. Barrachin, S. Bechta, D. Bottomley, L. Brissoneau, B. Cheynet, E. Fischer, C. Journeau, M. Kiselova, L. Mezentseva, P. Piluso, T. Wiss, Improvement of the european thermodynamic database NUCLEA, Progress in Nuclear Energy 52 (1) (2010) 84-96 (2010).

[29] B. Sundman, U. R. Kattner, M. Palumbo, S. G. Fries, OpenCalphad - a free thermodynamic software, Integrating Materials and Manufacturing Innovation 4 (1) (2015).

[30] B. Sundman, U. R. Kattner, C. Sigli, M. Stratmann, R. Le Tellier, M. Palumbo, S. G. Fries, The OpenCalphad thermodynamic software interface, Computational Materials Science 125 (2016) 188-196 (2016).

[31] J. M. Bonnet, J. M. Seiler, Thermohydraulic phenomena in corium pool: the bali experiment, in: Proc. of ICONE 7 , Tokyo, Japan, 1999 (1999).

[32] A. Shams, D. Dovizio, K. Zwijsen, C. L. Guennic, L. Saas, R. Le Tellier, M. Peybernes, B. Bigot, E. Skrzypek, M. Skrzypek, L. Vyskocil, L. Carenini, F. Fichot, Status of computational fluid dynamics for in-vessel retention: Challenges and achievements, Annals of Nuclear Energy 135 (2020) 107004 (2020).

[33] A. Pivano, P. Piluso, N. Chikhi, P. Fouquart, J. Delacroix, R. Le Tellier, Experiments on interactions of molten steel with suboxidized corium crust for in-vessel melt retention, Nuclear Engineering and Design 355 (2019) 110271 (2019).

[34] R. Zanella, R. L. Tellier, M. Plapp, G. Tegze, H. Henry, Three-dimensional numerical simulation of droplet formation by Rayleigh-Taylor instability in multiphase corium, Nuclear Engineering and Design 379 (2021) 111177 (Aug. 2021). 